\title{
Observed Evolution of the Tropical Atmospheric Water Cycle with Sea Surface Temperature ${ }^{\mathscr{D}}$
}

\author{
ERIK HÖJGÅRD-OLSEN \\ LATMOS/IPSL, Université de Versailles Saint-Quentin-en-Yvelines, CNRS, Guyancourt, and LMD/IPSL, Sorbonne \\ Université, École Polytechnique, CNRS, France \\ HÉLÈNE BROGNIEZ \\ LATMOS/IPSL, Université de Versailles Saint-Quentin-en-Yvelines, CNRS, Guyancourt, France \\ HÉLÈNE CHEPFER \\ LMD/IPSL, Sorbonne Université, École Polytechnique, CNRS, France
}

(Manuscript received 28 June 2019, in final form 31 December 2019)

\begin{abstract}
Better understanding of how moisture, clouds, and precipitation covary under climate warming lacks a comprehensive observational view. This paper analyzes the tropical atmospheric water cycle's evolution with sea surface temperature (SST), using for the first time, the synergistic dataset of instantaneous observations of the relative humidity profile from the Megha-Tropiques satellite, clouds from the CALIPSO satellite, and near-surface precipitation from the CloudSat satellite, and quantifies their rates of change with SST warming. The dataset is partitioned into three vertical velocity regimes, with cloudy grid boxes categorized by phase (ice or liquid), opacity (opaque or thin), and the presence of near-surface precipitation. Opaque cloud cover is always larger in the presence of near-surface precipitation (high ice clouds especially). Low liquid water clouds in the descending regime dominate for SSTs $<299.25 \mathrm{~K}$, where the free troposphere is dry $(\sim 20 \%)$, and opaque liquid water cloud cover decreases with SST warming $\left(-8 \% \mathrm{~K}^{-1}\right)$ and thin liquid water cloud cover stays constant $(\sim 20 \%)$. High ice clouds dominate the ascending regime in which, for $299.25<$ SST $<$ $301.75 \mathrm{~K}$, humidity increases with SST in the lower free troposphere and peaks around $302 \mathrm{~K}$. Over the warm SST range $(>301.75 \mathrm{~K})$, in the ascending regime, opaque high ice cloud cover decreases with SST $\left(-13 \% \mathrm{~K}^{-1}\right)$, while thin ice cloud cover increases $\left(+6 \% \mathrm{~K}^{-1}\right)$. Over the warm SST range, total cloudiness decreases with warming in all regimes. This paper characterizes fundamental relationships between aspects of the tropical atmospheric water cycle and SST.
\end{abstract}

\section{Introduction}

Previous studies (e.g., Ramanathan and Collins 1991; Pierrehumbert 1995; Inamdar and Ramanathan 1998; Fu et al. 2002) have discussed whether a self-regulating response to climate change allows the Earth system to modulate the outgoing longwave radiation (OLR) to prevent a runaway greenhouse effect. OLR is a function

Supplemental information related to this paper is available at the Journals Online website: https://doi.org/10.1175/JCLI-D-190468.s1.

Corresponding author: Erik Höjgård-Olsen, erik.hojgard-olsen@ latmos.ipsl.fr of surface temperature, atmospheric water vapor, and clouds (Roca et al. 2000), intimately studied under clearsky conditions (Goldblatt et al. 2013), while uncertainties remain in cloudy scenes (Stephens et al. 2016). We currently lack a comprehensive observational view of how moisture, clouds, and precipitation covary with surface warming at the instantaneous time scale, in both the upper and lower troposphere and under different large-scale forcing.

According to the iris hypothesis (Lindzen et al. 2001), OLR increases with surface warming due to decreasing high ice cloud cover. Namely, precipitation efficiency increases with surface temperature, which leads to less detrainment and smaller convective anvils. The Lindzen et al. (2001) paper was however disputed on account of 
their choice of 1) study region (the Pacific warm pool region), 2) identifying clouds by an infrared brightness temperature $<260 \mathrm{~K}$, and 3) representing sea surface temperature (SST) as a cloud-weighted parameter. These limitations were identified in the papers by Hartmann and Michelsen (2002), Lin et al. (2002), and Rapp et al. (2005).

Since then, it seems that model studies support an intensified hydrological cycle with more vigorous convective systems of greater precipitation efficiency (Allan and Soden 2008; Allan et al. 2014; Mauritsen and Stevens 2015; Bony et al. 2016), while observational work diverges. Li et al. (2019) found a positive IRIS feedback in the CESM model due to larger convective precipitation efficiency, less anvil detrainment, and thus thinner anvils. In the ascending branch of the tropical hydrological cycle some observational studies concluded on weak positive correlations between both upper-tropospheric cloudiness and SST, as well as precipitation efficiency and SST (e.g., Lin et al. 2006; Su et al. 2008), while others observed a narrowing and strengthening of the Hadley cell with smaller average cloud cover (Su et al. 2017). Low liquid water clouds in subsidence regions are another key uncertainty for climate sensitivity prediction (Bony et al. 2004; Bony and Dufresne 2005; Zhai et al. 2015; Kamae et al. 2016; Ceppi et al. 2017; Klein et al. 2017). This study quantifies the cloud cover evolution with SST under both strong ascent and strong descent in instantaneous observations.

Previous observational studies usually either 1) only observed one or two of the three key variables (humidity, clouds, precipitation) and only ever discussed the third; 2) lacked the instantaneous covariation between them; 3) lacked the detailed vertical structure (e.g., Dewey and Goldblatt 2018) by focusing only on the upper (Gettelman et al. 2006; Buehler et al. 2008) or lower troposphere (Ross et al. 2002; Läderach and Raible 2013); or 4) provided detailed observations but lacked the large-scale context by undersampling the tropical ocean (e.g., Rapp et al. 2005; Su et al. 2008).

In the present study, we build an observational-based understanding of how water vapor profiles, cloud properties (cover, phase, opacity), and near-surface precipitation $(750-1000 \mathrm{~m})$ vary together with tropical $\left(30^{\circ} \mathrm{S}-30^{\circ} \mathrm{N}\right) \mathrm{SST}$ at the instantaneous time scale. It uses four years (May 2012-April 2016) of instantaneous observations, to account for natural variability, collected by advanced satellites and subsequently analyzed together here for the first time. Relative humidity $(\mathrm{RH})$ profiles are provided by the microwave radiometer SAPHIR (Sounder for Atmospheric Profiling of Humidity in the Intertropics by Radiometry) onboard the Megha-Tropiques satellite, cloud characteristics by the CALIPSO (Cloud-Aerosol Lidar and Infrared Pathfinder Satellite Observation) lidar
CALIOP (Cloud-Aerosol Lidar with Orthogonal Polarization), and near-surface precipitation by the CloudSat Cloud Profiling Radar (CPR).

We first present the individual satellite datasets (section 2) and build the collocated composite dataset of the atmospheric water cycle at the instantaneous time scale and $1^{\circ} \times$ $1^{\circ}$ spatial resolution (section 3), which we refer to as the MTCC (Megha-Tropiques-CALIPSO-CloudSat) dataset. With the MTCC dataset, we perform statistical analyses of satellite data, based on instantaneous global-scale statistics of the key tropical atmospheric water cycle variables. We observe and analyze how the key tropical atmospheric water cycle variables covary instantaneously with each other and SST, under atmospheric large-scale ascent and descent separately (section 4). In section 5 we show that the abovementioned composite results are robust to natural climate variability such as El Niño and discuss the implications as well as limitations of the current work. We also compare our results to the iris hypothesis. Key messages are summarized in section 6.

\section{Data}

\section{a. Relative humidity from SAPHIR}

$\mathrm{RH}$ data are retrieved from the cross-track scanning, passive microwave radiometer SAPHIR onboard the Indo-French satellite Megha-Tropiques. Megha-Tropiques flies in a low-inclination orbit $\left(20^{\circ}\right.$ at the equator) at an altitude of $866 \mathrm{~km}$, which enables greater sampling of the tropical region $\left(30^{\circ} \mathrm{S}-30^{\circ} \mathrm{N}\right)$ compared to other previous lower observing platforms (Roca et al. 2015). It orbits the entire tropical belt within $100 \mathrm{~min}$, yielding $14-15$ orbits per day and 3-5 observations per day in the same location.

The SAPHIR microwave moisture sounder observes with a scan angle of $\pm 42.96^{\circ}$ around nadir and a swath of $1700 \mathrm{~km}$. SAPHIR measures the radiation emitted by water vapor in six channels around the $183.31-\mathrm{GHz}$ absorption line, yielding a moisture profile of RH data in six pressure layers. This allows for RH profile estimations from the upper troposphere (upper limit at $100 \mathrm{hPa}$ ) down to the boundary layer (lower limit at $950 \mathrm{hPa}$ ) under both clear and cloudy conditions, as long as the clouds do not produce large hydrometeors or ice crystals, characterized as deep convection or convective overshoots (Burns et al. 1997; Greenwald and Christopher 2002). SAPHIR is the first microwave sounder to provide direct observations of the moisture profile with six observing channels. Previous satellites typically observed the moisture profile with three [e.g., Advanced Microwave Sounding Unit B (AMSU-B)] or five channels (Advanced Technology Microwave Sounder). Compared to the other 183-GHz radiometers Microwave Humidity Sounder and AMSU-B, RH estimates derived from SAPHIR have a 
higher accuracy in the upper and lower troposphere, thanks to three additional channels located closer to the center and the wings (Brogniez et al. 2013).

The present study uses the instantaneous $1^{\circ} \times 1^{\circ}$ product $\mathrm{L} 2 \mathrm{~B}$, in which each $\mathrm{RH}$ pixel within a grid box is averaged and weighted by its uncertainty that is computed within the retrieval scheme (Sivira et al. 2017). Only $1^{\circ} \times 1^{\circ}$ grid boxes filled to more than $75 \%$ by pixels flagged as valid are considered in the gridded SAPHIR product, and in the MTCC dataset.

\section{b. Cloud properties from GOCCP}

In this study, cloud data are taken from the General Circulation Model-Oriented CALIPSO Cloud Product (GOCCP; Chepfer et al. 2010, 2013; Cesana and Chepfer 2012; Cesana et al. 2016), which consists of diagnosed cloud properties of CALIOP, which measures the attenuated backscatter at $532 \mathrm{~nm}$ with a horizontal resolution of $333 \mathrm{~m}$ and a $90-\mathrm{m}$ footprint size at ground level (Winker et al. 2009). CALIPSO flies as part of the near sun-synchronous A-Train constellation. It yields 15 orbits per day, each one crossing the equator twice daily at 0130 and 1330 local time (LT).

We use the latest version of the GOCCP product (GOCCP v.3.1.2; Guzman et al. 2017) with a spatial resolution of $1^{\circ} \times 1^{\circ}$. Each grid box contains the clear-sky cover, the opaque cloud cover, and the thin cloud cover, the sum of which equals $100 \%$. Opaque clouds (optical depth $>3-5$ ) fully attenuate the laser beam, while thin clouds (optical depths $<3-5$ ) do not. Most liquid clouds are opaque to the lidar, while most ice clouds are transparent to the lidar (Chepfer et al. 2014). In addition, GOCCP v.3.1.2 gives one value of $Z_{\text {OPAQUE, }}$ and one value of $Z_{\text {THIN }}$ in each grid box. The altitude $Z_{\text {OPAQUE }}$ is the center of the 480-m-thick altitudinal bin just below the altitude of full attenuation averaged over all the opaque cloud profiles in the grid box, and $Z_{\mathrm{THIN}}$ the altitude halfway between cloud top and cloud base in a thin cloud (Vaillant de Guélis et al. 2017). In the present study cloudy grid boxes are defined as grid boxes of total cloudiness (opaque plus thin cloud cover within a grid box) $>5 \%$ and clear-sky grid boxes as grid boxes of total cloudiness $\leq 5 \%$.

We further categorize cloudy objects after phase (liquid or ice). Previous publications have discussed the altitude at which tropical ice clouds form. Typically, it is located above $600 \mathrm{hPa}$ (Li et al. 2012; Cesana et al. 2012, 2016). No further information is provided by the CALIPSO lidar for altitudes below $Z_{\text {OPAQUE}}$. Therefore, we distinguish between low liquid water clouds where $Z_{\text {OPAQUE }}\left(Z_{\text {THIN }}\right)<$ $5 \mathrm{~km}$ (labeled "Only Liquid" clouds) and high ice clouds where $Z_{\text {OPAQUE }}\left(Z_{\text {THIN }}\right)>5 \mathrm{~km}$ (labeled "Ice" clouds). This approximate cloud phase distinction at $5-\mathrm{km}$ altitude is chosen for the present study based on Fig. 7 in Cesana and Chepfer (2013) but should not be confused with the cloud masks built for the GOCCP product by them.

\section{c. Near-surface precipitation from CloudSat}

CloudSat flies as part of the A-Train (10-15 s behind CALIPSO) and carries a $94-\mathrm{GHz}$ cloud profiling radar, designed to profile atmospheric hydrometeors (Haynes et al. 2009). Its vertical resolution is $480 \mathrm{~m}$ and the footprint $1.4 \mathrm{~km}$ in diameter at the surface with an alongtrack resolution of $1.8 \mathrm{~km}$ and a minimum detection signal of $-30 \mathrm{~dB} Z$ (Smalley et al. 2014). For the purpose of this work, a $1^{\circ} \times 1^{\circ}$ gridded version of the CloudSat Data Processing Center's 2C-PRECIP-COLUMN (v. P_R05; Haynes et al. 2013) product is used for nearsurface precipitation detection over tropical oceans. Over open ocean surfaces, the 2C-PRECIP-COLUMN product assesses the likelihood of near-surface precipitation between 750 and $1000 \mathrm{~m}$ by applying near-surface reflectivity thresholds as well as estimating the pathintegrated attenuation from the surface backscatter (Smalley et al. 2014). In the gridded product, local solar daytime and nighttime granule files are gridded separately using a uniform $1^{\circ} \times 1^{\circ}$ grid and filtered with respect to the $2 \mathrm{C}$-PRECIP-COLUMN quality flags (Status_flag $<8$ ). We partition cloudy grid boxes by the presence of near-surface precipitation or not, which in the gridded product are manifested by the flags "clear sky" for no near-surface precipitation and "rain possible", "rain probable," and "rain certain" for the presence of near-surface precipitation (Haynes et al. 2013). Precipitating grid boxes therefore include all rain rates from drizzle to heavy precipitation. We make no distinction between rainfall rates in the figures we show, but comment on the evolution in heavily precipitating ( $\gtrsim 72 \mathrm{~mm} \mathrm{day}^{-1}$ in the tropics; Kay et al. 2018) situations. We then compute the near-surface precipitation cover within a precipitating grid box as the accumulated number of precipitating profiles, divided by the total number of profiles.

\section{d. Sea surface temperature and vertical pressure velocity from ERA5}

We combine the above-mentioned satellite datasets with SST and vertical pressure velocity at the 500-hPa level $\omega_{500}$ from the fifth generation of the European Centre for Medium-Range Weather Forecasts (ECMWF) reanalysis (ERA5), where $\omega_{500}$ is used as a proxy for the large-scale circulation. ERA5 is produced from 4D-Var data assimilations of the ECMWF Integrated Forecast System and is given in hourly values with a horizontal resolution of $\sim 31 \mathrm{~km}\left(0.3^{\circ} \times 0.3^{\circ}\right)$ in 137 vertical hybrid sigma-pressure levels (Dee et al. 2011; Hoffmann et al. 2018). Since the 
$\omega_{500}$ parameter is arguably sensitive to local dynamics and subject to significant biases at the instantaneous scale (Trenberth et al. 2000), we average the hourly ERA5 $\omega_{500}$ to monthly mean values. Because SST is a much more homogeneously distributed parameter than $\omega_{500}$, and fluctuates on longer time scales, it is deemed reliable on the hourly scale. We take the mean of the 1300 and 1400 LT SST values as the $1330 \mathrm{LT}$ value (when the A-Train crosses the equator). The full tropical belt $\left(30^{\circ} \mathrm{S}-30^{\circ} \mathrm{N}\right)$ is considered to avoid local and regional biases but limited to fully oceanic grid boxes to exclude biases that could arise due to land-ocean contrasts or the diurnal cycle over land (Noel et al. 2018).

\section{Methods}

\section{a. Collocation}

As CALIPSO and CloudSat are both part of the A-Train constellation, these satellite data are collocated by design. Only daytime data (01:30 p.m.) are available for CloudSat since 2011, when a battery failure occurred. Therefore, because Megha-Tropiques was launched in October 2011, the present study only considers daytime observations. When collocating the SAPHIR dataset with the A-Train datasets, a 2-h time window is allowed around 1330 LT for SAPHIR to scan the same GOCCP $1^{\circ} \times 1^{\circ}$ grid box. We assume that the atmospheric state does not change radically within this 2 -h time frame. Then, validated $1^{\circ} \times 1^{\circ}$ grid boxes from SAPHIR $(\mathrm{RH})$ are collocated with GOCCP (cloud) and CloudSat (nearsurface precipitation), in which all grid boxes containing at least one profile are used. These collocated grid boxes are then collocated with the ERA5 datasets of SST (at $1330 \mathrm{LT}$ ) and $\omega_{500}$ (monthly values).

\section{b. Atmospheric circulation regimes}

Konsta et al. (2012) characterized clouds and cloud properties using CALIPSO-GOCCP and MODIS (Moderate Resolution Imaging Spectroradiometer) observations in three $\omega_{500}$ regimes; 1$) \omega_{500}<-20 \mathrm{hPa}$ day $^{-1}$, 2) $-20<\omega_{500}<20 \mathrm{hPa} \mathrm{day}^{-1}$, and 3) $\omega_{500}>20 \mathrm{hPa} \mathrm{day}^{-1}$. Here we partition the MTCC dataset into the same dynamical regimes. Figure 1a shows the climatological mean state of cloud fraction profiles plotted as a function of $\omega_{500}$. As in Konsta et al. (2012), two sections of large cloud fractions stand out: 1) high ice clouds for strongly negative $\omega_{500}\left(<-20 \mathrm{hPa} \mathrm{day}^{-1}\right)$ and 2$)$ low liquid water clouds for strongly positive $\omega_{500}\left(>20 \mathrm{hPa} \mathrm{day}^{-1}\right.$ ) (separated by the horizontal gray line in Fig. 1a). The respective $\omega_{500}$ ranges of these two sections overlap in the interval $-20<\omega_{500}<$ $20 \mathrm{hPaday}^{-1}$, with smaller fractions of both low liquid water clouds and high ice clouds. The ascending regime appears to be dominated by high ice clouds in the MTCC dataset, when in fact low liquid water clouds likely coexist with these (though not represented in MTCC when they occur below $Z_{\text {OPAQUE}}$ ). Low liquid water clouds dominate the descending regime.

Figure $1 \mathrm{~b}$ shows the resemblance between the $\omega_{500}$ distributions of the undersampled MTCC dataset (solid blue) and the full time period without regard to satellite overpasses (black). The MTCC dataset samples less than $1 \%$ of the ERA5 grid boxes, but because regime percentages are sampled similarly (differing by $2 \%$ ), the MTCC dataset is deemed representative of the tropical oceans. In all, $42 \%$ of the MTCC grid boxes are sampled in the intermediate regime, $37 \%$ in the descending regime, and $21 \%$ in the ascending regime. The dataset is dominated by nonprecipitating scenes, but when nearsurface precipitation occurs (dashed blue), it is most frequent in the intermediate regime $(41 \%)$, and about equally frequent in the ascending $(29 \%)$ and descending regimes $(30 \%)$.

\section{c. Summary of the synergistic dataset}

The MTCC dataset is summarized in Table 1. It covers the tropical oceanic region $\left(30^{\circ} \mathrm{S}-30^{\circ} \mathrm{N}\right)$ with a spatial resolution of $1^{\circ} \times 1^{\circ}$ and consists of once daily $(\sim 1330$ LT) collocated instantaneous observations of RH profiles, cloud cover, and SST, within three monthly mean $\omega_{500}$ regimes. Cloudy grid boxes (cloudiness $>5 \%$ ) are further categorized according to phase (high ice or low liquid), opacity (opaque or thin), and the presence of near-surface precipitation. Thus, the entire tropical belt is represented by 27 categories: three categories of clearsky cover $\geq 95 \%$ (one for each $\omega_{500}$ regime) and 24 cloudy categories $\left(3 \omega_{500}\right.$ regimes $\times 2$ phases $\times 2$ opacities $\times 2$ near-surface precipitation criteria). From this point on, only once daily grid boxes where data for all parameters are available, within each regime and category, are considered in the MTCC dataset.

Figure 2 shows the multiannual mean state of the MTCC parameters at 1330 LT. As expected, the strongest convection is found in a narrow band along the intertropical convergence zone (ITCZ). This is the region of the highest SSTs (Fig. 2a), least negative RH gradient (Fig. 2c), greatest occurrence of near-surface precipitation (Fig. 2d), and widest high ice phase clouds (Figs. 2e,f). High ice and low liquid water clouds cover on average equally much of the tropical oceans (33\% and $34 \%$, respectively), but represent different regions (the ITCZ and the stratocumulus regions off the west coast of continents, respectively). While thin clouds cover most of the high ice phase regions, opaque clouds cover more of the low liquid water phase regions. The standard deviations of the instantaneous $\omega_{500}$, near-surface 

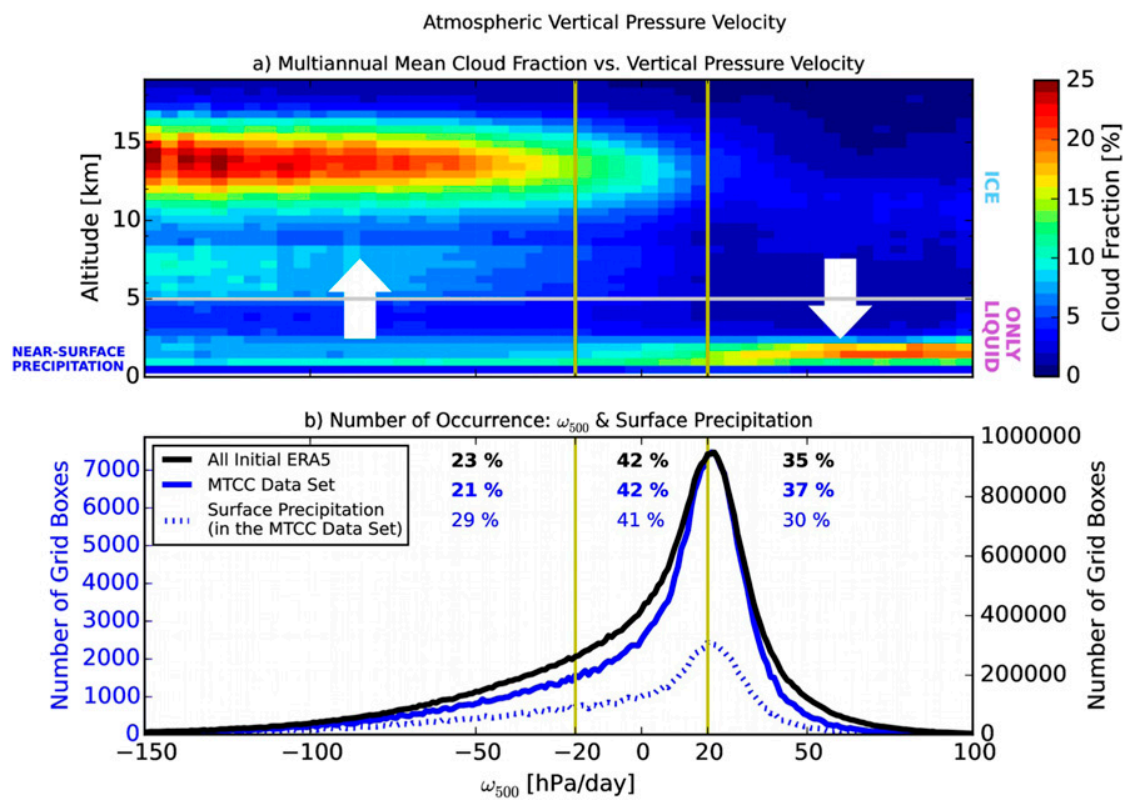

FIG. 1. (a) Multiannual mean cloud fraction profiles as a function of vertical pressure velocity. The horizontal line represents the $Z=5$-km level, which separates ice and only liquid phase clouds in the present study. The altitude at which "near-surface precipitation" is referred to $(750-1000 \mathrm{~m})$ is also highlighted. (b) Distributions of grid boxes sorted by monthly mean $\omega_{500}$ for ERA5 data sampled over the tropical oceans from May 2012 to April 2016 (black), the remaining $\omega_{500}$ data in the collocated MTCC dataset (solid blue), and the subset of the collocated MTCC data containing near-surface precipitation (dashed blue). Percentages show the contribution of each regime to the total number of grid boxes in the respective distributions. The right $y$ axis belongs to the black curve, while the left $y$ axis belongs to the two blue curves.

precipitation frequency of occurrence, and cloud covers show large spreads around their respective mean values (indicating wide ranges of local and instantaneous values not captured by the color bars corresponding to the mean values in Fig. 2).

\section{d. Statistical aspects of the representation of the collocated instantaneous dataset}

The results in section 4 below are presented solely for the instantaneous scale, in order to avoid smoothed averages and certify that the same situations are viewed and compared for moisture, clouds, and near-surface precipitation. The median cloud cover and moisture profile evolutions with SST shown in section 4 are only computed for $0.25-\mathrm{K} \mathrm{SST}$ bins that include at least five instantaneous observations. A bootstrapping algorithm is then applied to the data within each $0.25-\mathrm{K}$ SST bin to remove statistically unlikely median values. (In addition, evolutions calculated for SST bins containing less than 100 grid boxes are shaded by a gray filter in Figs. 5 and 8, as well as in Fig. S3 in the online supplemental material, to acknowledge their weaker significance.)

Because OLR increases nonlinearly with free-tropospheric moisture (Allan et al. 1999; Roca et al. 2000), changes in low humidity have a larger effect on the OLR than changes in high humidity. Therefore, when $\mathrm{RH}$ is compared (in Figs. 5 and 8 and Fig. S3), the relative RH difference is favored over the absolute difference.

\section{Analyses of the tropical atmospheric water cycle's variation with $\mathrm{SST}$ in different regimes}

\section{a. Cloud cover variations with SST}

Figure 3a shows the distributions of the three $\omega_{500}$ regimes with SST. The descending regime dominates the cold SST range $(<299.25 \mathrm{~K})$ and the ascending regime dominates the warm SST range $(>301.75 \mathrm{~K})$. Both regimes have significant impact on the moderate SST range $(299.25<\mathrm{SST}<301.75 \mathrm{~K})$ as well; otherwise they are dominated by the intermediate regime. Figure $3 \mathrm{~b}$ shows that the middle troposphere is driest in the descending regime and moistest in the ascending regime (more than twice as moist as the descending) and that there is little difference between the regimes in the boundary layer and at the top of the troposphere.

After examining how the atmospheric circulation is tied to SST (Fig. 3a), we now examine how the cloud cover within a grid box varies with SST (Fig. 3c). 


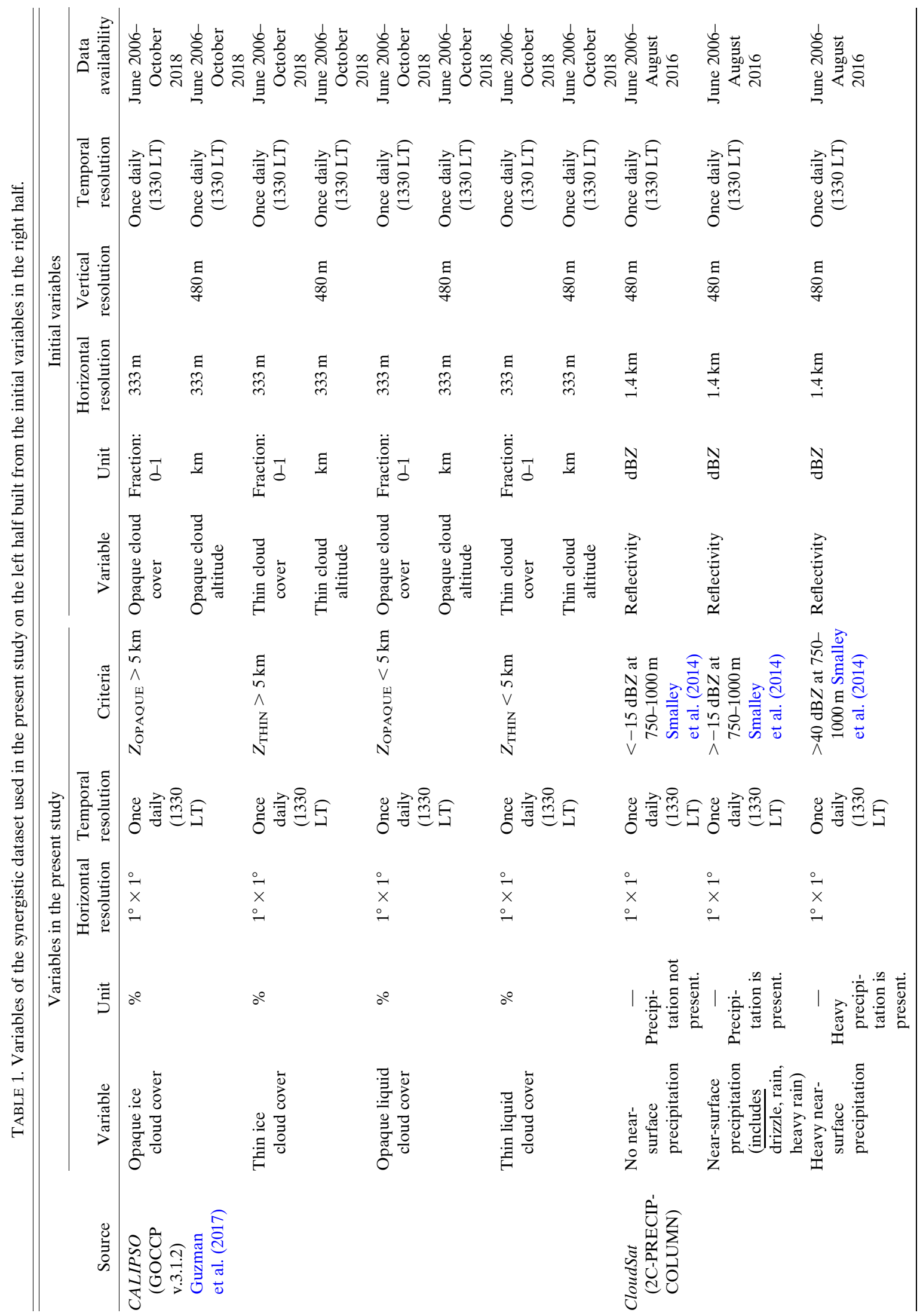




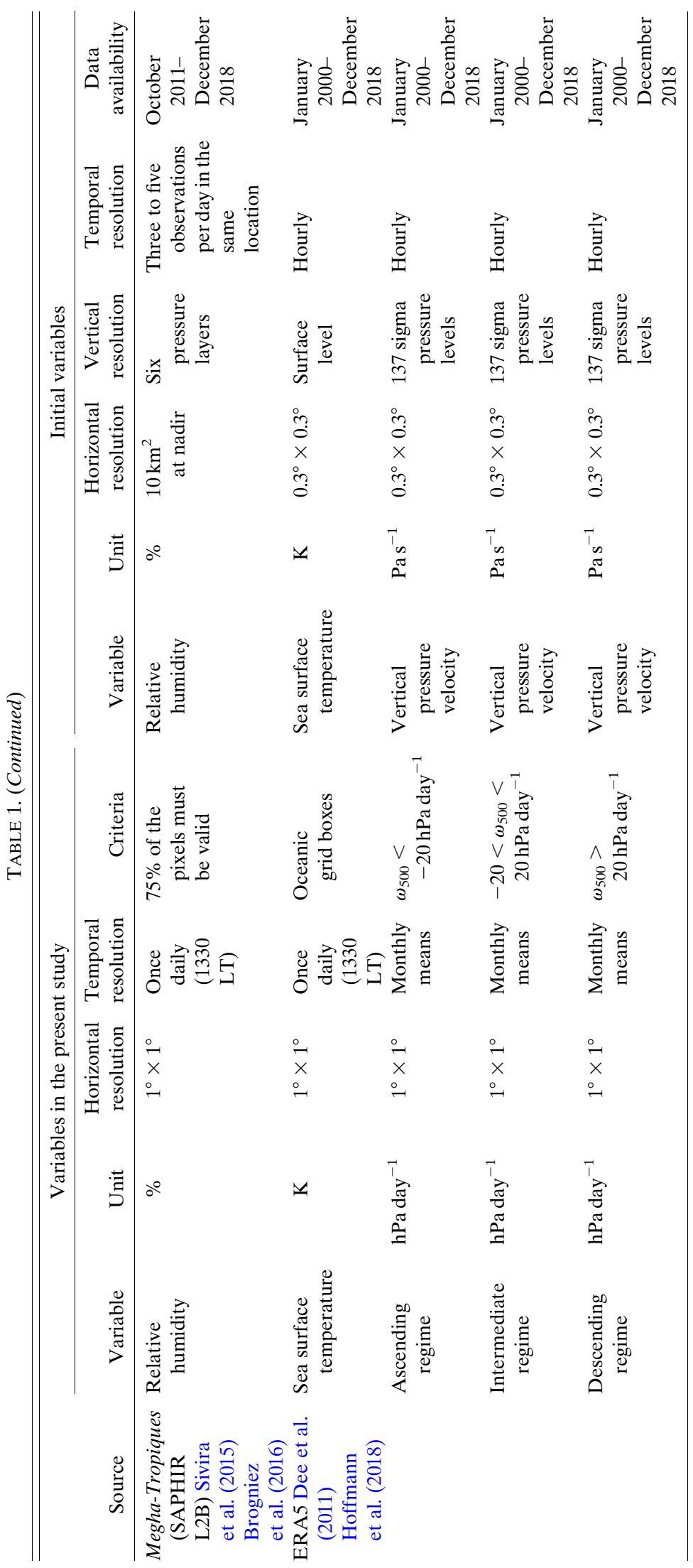



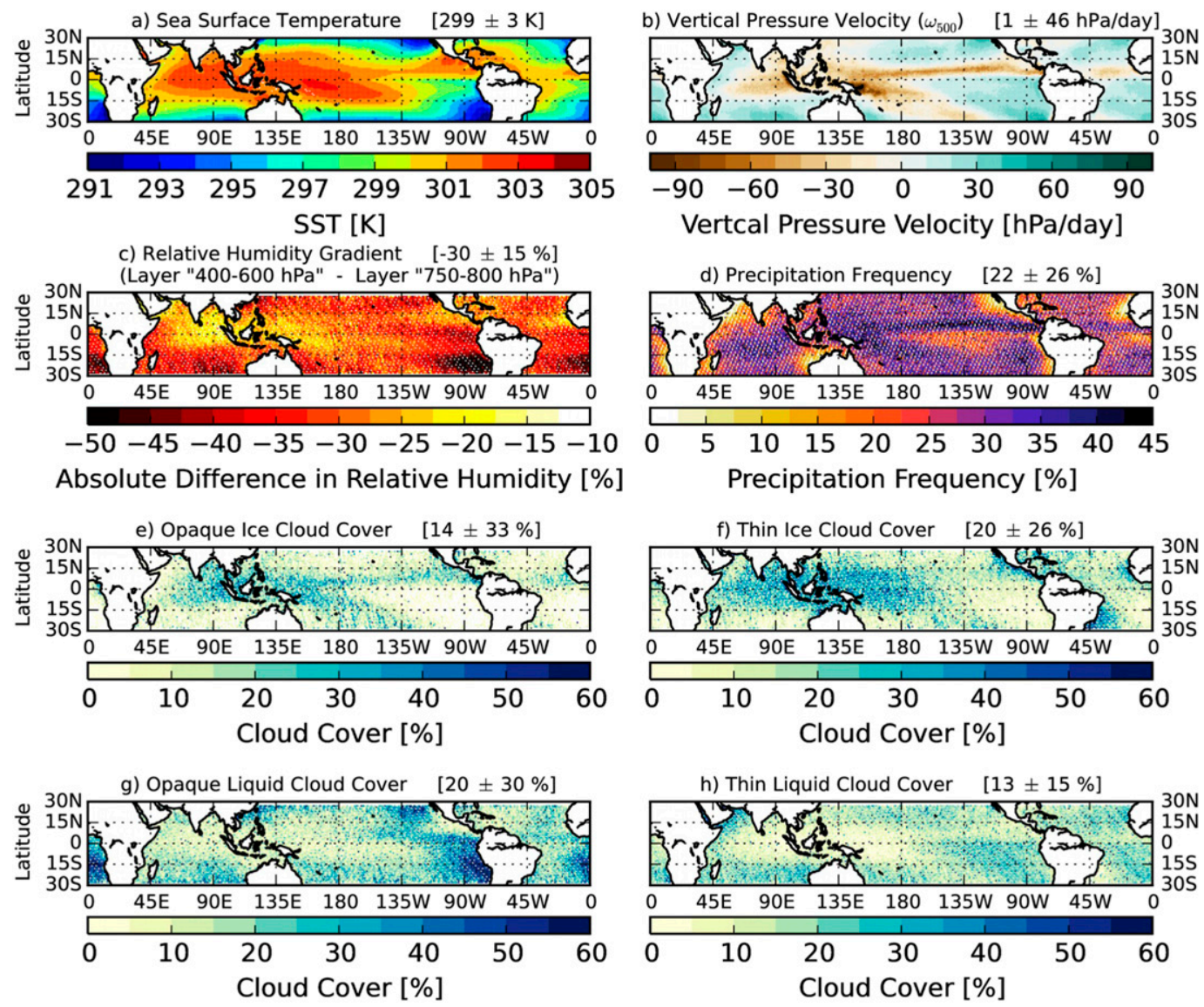

FIG. 2. Maps of multiannual gridbox mean (a) sea surface temperature, (b) vertical pressure velocity, (c) relative humidity gradient (from layer " $400-600 \mathrm{hPa}$ " to layer " $750-800 \mathrm{hPa}$ "), (d) near-surface precipitation frequency, (e) opaque ice cloud cover, (f) thin ice cloud cover, (g) opaque low liquid cloud cover, and (h) thin low liquid cloud cover at 1330 LT. Values in brackets are the tropical oceanic multiannual means over the time period May 2012April 2016 plus or minus their standard deviations.

Figure $3 \mathrm{c}$ shows the median gridbox cloud cover evolution within each $\omega_{500}$ regime, as well as over the whole tropics ("All Regimes"; solid black curve). In the descending regime, the cloud cover decreases almost monotonically with SST. In contrast, the cloud cover evolution in the intermediate regime shows a transition that can be defined by a local minimum at $299.25 \mathrm{~K}$ and the evolutions in both the ascending and intermediate regimes show transitions defined by local maxima at $301.75 \mathrm{~K}$. Throughout the rest of the paper, we refer to these transitions as the cold and warm SST thresholds. Our cold SST threshold (299.25 K; Fig. 3) is consistent with the SST range (298-301 K) previously discussed as the onset of tropical deep convection, (Johnson and Xie 2010; Evans and Webster 2014; Aumann et al. 2017) and our warm SST threshold (301.75 K; Fig. 3) with where the frequency distribution of deep convective systems typically peaks (Waliser et al. 1993; Sabin et al. 2013; Houze et al. 2015).
Over the warm SST range, cloud cover decreases in all three regimes (Fig. 3c), an observation we have not seen before. Each regime likely includes dynamical as well as thermodynamical components. For example, the descending (ascending) regime is sampled over a narrow $\omega_{500}$ (SST) range while a wide range of SSTs (negative $\omega_{500}$ values). The regime cloud cover decreases in all regimes over the 4-yr time period, fluctuating on annual time scales ( $\sim 12$ months) in the descending and intermediate regimes, while on shorter time scales ( $\sim 6$ months) in the ascending regime (not shown).

For comparison with previous work, Fig. 3d shows the cloud cover evolutions with SST of the cloud types identified by the CloudSat 2B-CLDCLASS product in Behrangi et al. (2012). The colors represent the regimes where these cloud types are likely sampled. The cloud cover variations with SST in Figs. $3 c$ and $3 \mathrm{~d}$ agree to a first order in the ascending and descending regimes, but discrepancies are expected when 

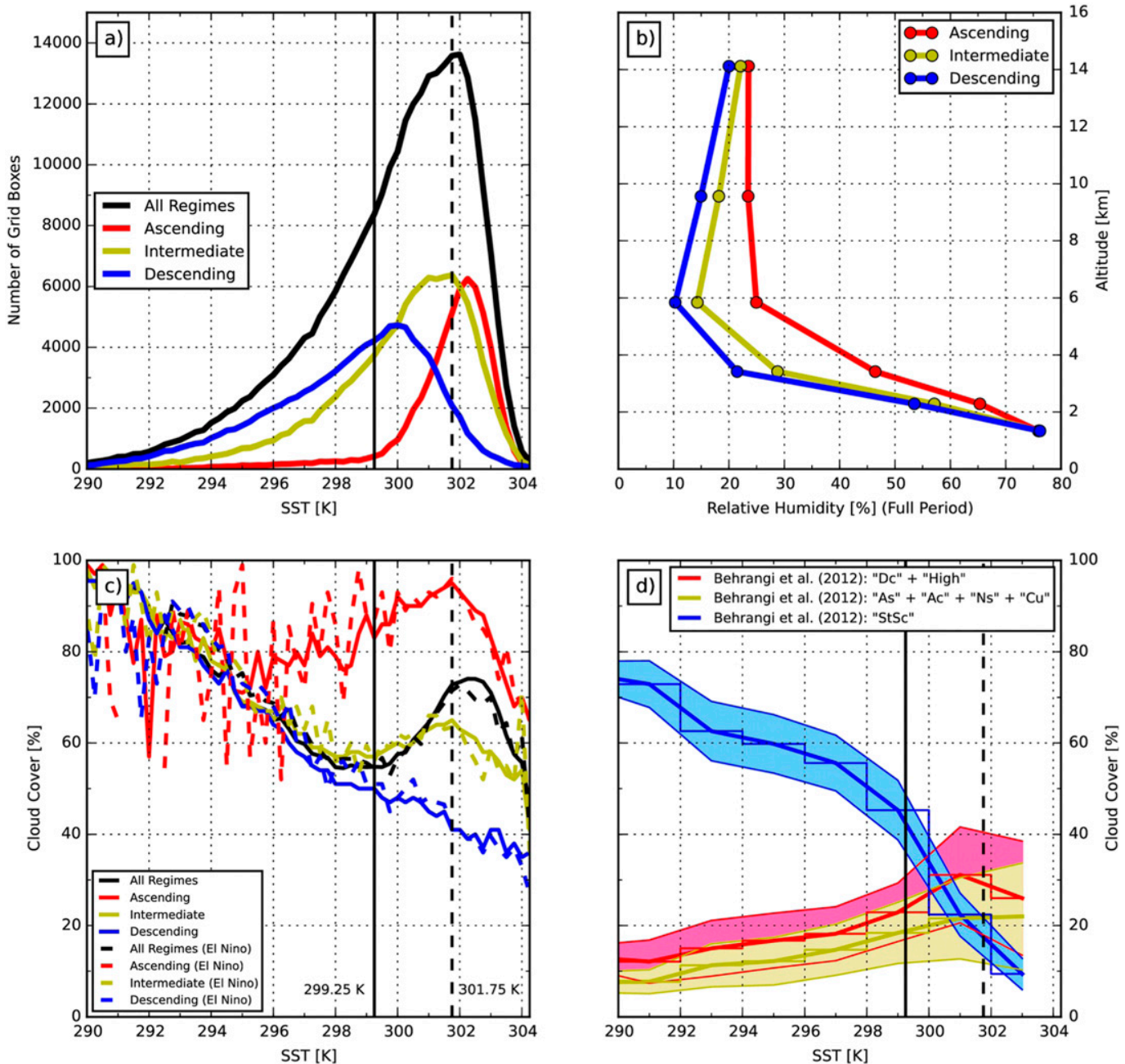

FIG. 3. (a) Number distribution (gridbox sampling) with SST of the full MTCC dataset (black) as well as within the three $\omega_{500}$ regimes. (b) Mean RH profiles over the full SST range for the three $\omega_{500}$ regimes. (c) Median cloud cover for the individual $\omega_{500}$ regimes as well as without regime consideration (black). Solid lines are for the full period (May 2012-April 2016) and dashed lines are for the El Niño period (May 2015-April 2016). (d) Evolutions of regime-accumulated cloud type cover from Table 1 in Behrangi et al. (2012). The central line for each regime is the sum over the single cloud types in Table 1 in Behrangi et al. (2012), in the present paper deemed to belong to the respective regime. The shading illustrates the uncertainty around the central line, taken as the sum of the two distinct cloud type values in Table 1 in Behrangi et al. (2012). Vertical lines are the SST thresholds at 299.25 (solid) and $301.75 \mathrm{~K}$ (dashed).

comparing regime-median cloud cover variations to cloud type variations. Also, CALIOP (present study) captures thin clouds unresolved by CPR (Behrangi et al. 2012), which could partly explain the overall smaller cloud cover in Fig. 3d compared to Fig. 3c. Figure S1 in the online supplemental material shows comparisons with previous observational studies that identified clouds by brightness temperature and assumed linear relationships between high ice cloud cover and cloud-weighted SST (Table 2). The cloudweighting flattens the fluctuations in the instantaneous cloud cover evolutions, which could explain why previous studies plotted linear regressions and missed the nonlinearity over the moderate and warm SST ranges.

Because Fig. 3c shows that the cloud cover varies differently with SST in different regimes, we now examine each of them independently and characterize how $\mathrm{RH}$, clouds, and near-surface precipitation covary with SST. For this purpose, we make use of the full MTCC dataset (relying on the cloud types defined in section 3) and discuss their variations within each SST range; cold $(<299.25 \mathrm{~K})$, moderate $(299.25<\mathrm{SST}<301.75 \mathrm{~K})$, and warm $(>301.75 \mathrm{~K})$. 
TABLE 2. Study setup in some previous works dedicated to the tropical cloud cover evolution with SST.

\begin{tabular}{|c|c|}
\hline Author & Study setup \\
\hline Lindzen et al. (2001) & $\begin{array}{l}\text { Data source: Japanese Meteorological } \\
\text { Geostationary Satellite } \\
\text { Area: } 30^{\circ} \mathrm{S}-30^{\circ} \mathrm{N}, 130^{\circ} \mathrm{E}-170^{\circ} \mathrm{W} \text { (Pacific } \\
\text { warm pool region) } \\
\text { Time period: } 1 \text { Jan } 1998-31 \text { Aug } 1999 \\
\text { SST range: } 298-303 \mathrm{~K} \text { (cloud- } \\
\text { weighted SST) } \\
\text { Separated clouds with brightness } \\
\text { temperature } \mathrm{BT}_{11 \mu \mathrm{m}}<220 \mathrm{~K} \text { and } \\
\mathrm{BT}_{11 \mu \mathrm{m}}<260 \mathrm{~K}\end{array}$ \\
\hline Rapp et al. (2005) & $\begin{array}{l}\text { Data source: TRMM (VIRS) } \\
\text { Area: } 30^{\circ} \mathrm{S}-30^{\circ} \mathrm{N}, 130^{\circ} \mathrm{E}-170^{\circ} \mathrm{W} \text { (Pacific } \\
\quad \text { warm pool region) } \\
\text { Time period: } 1 \mathrm{Jan} 1998-31 \text { Aug } 1999 \\
\text { SST range: } 294-304 \mathrm{~K} \\
\text { Cloud size normalized by rainfall amount; } \\
\text { separated single and multicore } \\
\text { convective systems } \\
\text { Separated systems with brightness } \\
\quad \text { temperature } \mathrm{BT}_{11 \mu \mathrm{m}}<250 \mathrm{~K},<260 \mathrm{~K} \text {, } \\
\quad<270 \mathrm{~K}\end{array}$ \\
\hline Lin et al. (2006) & $\begin{array}{l}\text { Data source: TRMM (CERES, } \\
\text { TMI, VIRS) } \\
\text { Area: } 30^{\circ} \mathrm{S}-30^{\circ} \mathrm{N} \text {; resolution: } 1^{\circ} \times 1^{\circ} \text {; } \\
\quad \text { oceanic grid boxes } \\
\text { Time period: } 1 \text { Jan } 1998-31 \text { Aug } 1998 \\
\text { SST range: } 290-305 \mathrm{~K} \\
\text { Evolution of deep convective system's } \\
\quad \text { areal cover with SST }\end{array}$ \\
\hline Su et al. (2008) & $\begin{array}{l}\text { Data source: AIRS (cloud fraction at } \\
\text { pressure }<300 \mathrm{hPa} \text { ) } \\
\text { Area: } 15^{\circ} \mathrm{S}-15^{\circ} \mathrm{N} \text {, tropical oceanic region } \\
\text { Time period: } 1 \text { Sep } 2002-30 \text { Sep } 2006 \\
\text { SST range: } 300.8-302.6 \mathrm{~K} \text { (cloud- } \\
\quad \text { weighted SST) }\end{array}$ \\
\hline Behrangi et al. (2012) & $\begin{array}{l}\text { Data source: } C A L I P S O \text { (2B-GEOPROF) } \\
\text { and CloudSat (2B-CLDCLASS) } \\
\text { Area: } 30^{\circ} \mathrm{S}-30^{\circ} \mathrm{N} \text {; resolution: } 3^{\circ} \times 3^{\circ} ; \\
\quad \text { oceanic grid boxes } \\
\text { Time period: } 1 \text { Jan } 2007-31 \text { Dec } 2008 \\
\text { SST range: } 291-304 \mathrm{~K} \\
\text { Separated clouds into nine classes with } \\
\text { CloudSat (2B-CLDCLASS) }\end{array}$ \\
\hline
\end{tabular}

\section{b. Covariation of RH, clouds, and near-surface precipitation with SST in the descending regime}

We first examine the horizontal extent of clouds in the descending regime $\left(\omega_{500}>20 \mathrm{hPa} \mathrm{day}^{-1}\right)$, by counting the number of cloudy grid boxes (Fig. 4). This regime covers $36.8 \%$ of the full tropical belt, where the area containing clouds accounts for $36.1 \%$. Low liquid water clouds without near-surface precipitation is the dominant category in the descending regime $(18.0 \%)$ and low liquid water clouds with near-surface precipitation contribute the second most (9.9\%). Most of the clouds are located over the moderate SST range, and the number distributions peak around $300 \mathrm{~K}$ (Fig. 4).

Next, we examine how the low liquid water cloud cover within a grid box varies with SST (Figs. 5a-c). The low liquid water cloud cover is decomposed into opaque and thin low liquid water clouds with or without nearsurface precipitation. Regardless of near-surface precipitation category, the opaque low liquid water cloud gridbox cover decreases monotonically with warming over the whole SST range, while the thin low water liquid cloud gridbox cover is largely constant.

We finally describe how the RH profile within a grid box varies with SST (Figs. 5d-f). In the descending regime, only the lower troposphere is moist and the moistest $(>75 \%)$ for the coldest SSTs. RH is higher in the free troposphere over the cold SST range and in the presence of nonprecipitating low liquid water clouds, while the free troposphere is moister when these clouds precipitate over the moderate and warm ranges (Fig. 5f).

Figure 6 shows how the tropical atmosphere changes when SST warms $1 \mathrm{~K}$. The individual bullets in the top panel are weighted by their number contribution to the whole descending regime. Because low liquid water clouds without near-surface precipitation dominate the descending regime, we first analyze the influence of $1-\mathrm{K}$ SST increase on this cloud population (pink circles in Figs. 6a-c). Over all SST ranges, an increase of 1-K SST is associated with a boundary layer drying (Figs. 6d,e) and decreasing opaque low liquid water cloud gridbox cover (Figs. 6a-c). Over the cold SST range, we simultaneously observe a boundary layer drying $\left(-2 \% \mathrm{~K}^{-1}\right)$ and the greatest decrease in opaque low liquid water cloud cover $\left(-8 \% \mathrm{~K}^{-1}\right)$. Meanwhile, the overall tropical area containing these clouds increases slightly (the number of grid boxes increases $+0.1 \% \mathrm{~K}^{-1}$; not shown), suggesting that the condensed water is distributed over a larger portion of the tropical belt. Similarly, over the moderate SST range, a $1-\mathrm{K}$ increase of SST is associated with a slightly drier boundary layer $(-1 \%)$, a moistening of the middle troposphere $(+2 \%)$, and decreasing nonprecipitating low liquid water gridbox cloud cover $\left(-1 \% \mathrm{~K}^{-1}\right)$. The overall area containing these clouds decreases as well $\left(-0.2 \% \mathrm{~K}^{-1}\right.$; not shown), leading to a possible decrease in the amount of nonprecipitating condensed water.

The second most important cloud population is precipitating low liquid water clouds (red circles in Figs. 6a-c), whose responses in RH and cloud cover to a 1-K SST warming are of the same signs as the nonprecipitating situations (pink circles). The opaque cloud amplitude response is however stronger in nonprecipitating situations over the cold SST range $\left(-8 \% \mathrm{~K}^{-1}\right)$ while in the presence of near-surface precipitation $\left(-6 \% \mathrm{~K}^{-1}\right)$ over the moderate SST range. 


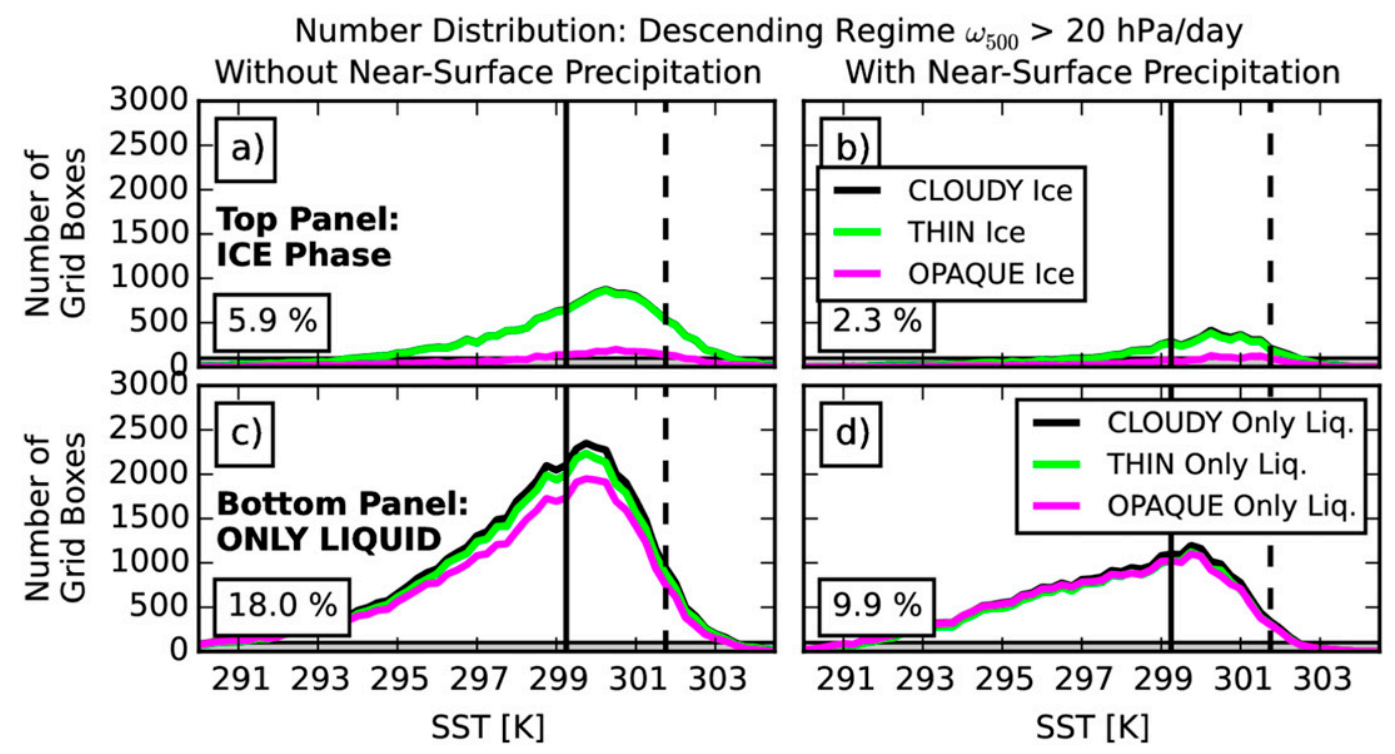

FIG. 4. Gridbox number distributions with SST for the descending regime: $\omega_{500}>20 \mathrm{hPa} \mathrm{day}^{-1}$. Occurrence of grid boxes containing (a) ice clouds but no near-surface precipitation, (b) ice clouds and near-surface precipitation, (c) only liquid clouds but no near-surface precipitation, and (d) only liquid clouds and near-surface precipitation. Vertical lines are for the same SST thresholds as identified in Fig. 3.

Decreasing marine boundary layer cloud cover with warming has been shown in previous observational studies (Eastman et al. 2011; Behrangi et al. 2012; Zhai et al. 2015). Behrangi et al. (2012) found decreasing stratus and stratocumulus cloud cover with SST (Fig. 3d) and Zhai et al. (2015) observed decreasing monthly mean marine boundary layer cloud fractions in the merged CloudSat and CALIPSO cloud product over the SST range $291-299 \mathrm{~K}$ in the subsidence regions $\left(20^{\circ}-40^{\circ} \mathrm{N} / \mathrm{S}\right)$. The largely constant thin low liquid water cloud cover with warming (Figs. 5a,b) clarifies that the decreasing low liquid water cloud cover is due to decreasing opaque low liquid water cloud cover with warming, whose evolution appears consistent with these previous publications and which we expect represents the transition from stratus clouds to stratocumulus.

\section{c. Covariation of RH, clouds, and near-surface pre- cipitation with SST in the ascending regime}

Figure 7 displays the gridbox sampling of the ascending regime $\left(\omega_{500}<-20 \mathrm{hPa} \mathrm{day}^{-1}\right)$ with SST. This regime covers $21.1 \%$ of the overall tropical belt and is dominated by high ice clouds (14.5\%). Low liquid water clouds cover only $6.6 \%$. Most of these clouds occur over the moderate and warm SST ranges with a maximum occurrence at $302.25 \mathrm{~K}$ (Figs. 7 and 3a).

Figures $8 \mathrm{a}$ and $8 \mathrm{~b}$ show how opaque and thin high ice cloud cover within a grid box vary with SST. Over the moderate SST range, the grid boxes containing opaque high ice clouds are almost fully overcast $(>80 \%)$, whereas over the warmest SST range the opaque high ice cloud cover decreases with SST, possibly in favor of increasing thin high ice cloud cover. Moreover, the presence of near-surface precipitation is associated with larger opaque high ice cloud gridbox cover $(+40 \%)$.

Figures $8 \mathrm{~d}$ and $8 \mathrm{e}$ show that the boundary layer and the middle troposphere are moist $(>60 \%)$ in the presence of high ice clouds, but the $\mathrm{RH}$ profile varies with SST. Hatched areas in Fig. 8 indicate where the interquartile range (IQR) of RH is greater than $35 \%$ (Fig. S7). In these areas we recall the potentially dry bias in SAPHIR where deep convective profiles are discarded on account of the scattering by their large ice crystals (Brogniez et al. 2013). Over the moderate SST range, humidity increases with SST in the lower free troposphere and peaks around the warm SST threshold $(301.75 \mathrm{~K})$, indicative of rising altitude of convective mixing and cloud development. The free-tropospheric RH $($ FTRH) is greater in precipitating compared to nonprecipitating scenes (up to $40 \%$ ) over the full SST range. In fact, in the presence of heavy near-surface precipitation (not shown), RH $>65 \%$ in all free-tropospheric layers, while the boundary layer is dry $(\sim 45 \%)$.

Figure 9 shows the rate of change of cloud covers and RH associated with a 1-K SST increase in the ascending regime. As scenes containing high ice clouds with nearsurface precipitation dominate this regime, we first analyze the changes in this population (dark blue squares and profiles in Fig. 9, center and right columns). 
$\omega_{500}>20 \mathrm{hPa} /$ day: Clouds in ONLY LIQUID Phase

Evolutions of Cloud Cover and Relative Humidity within a Grid Box

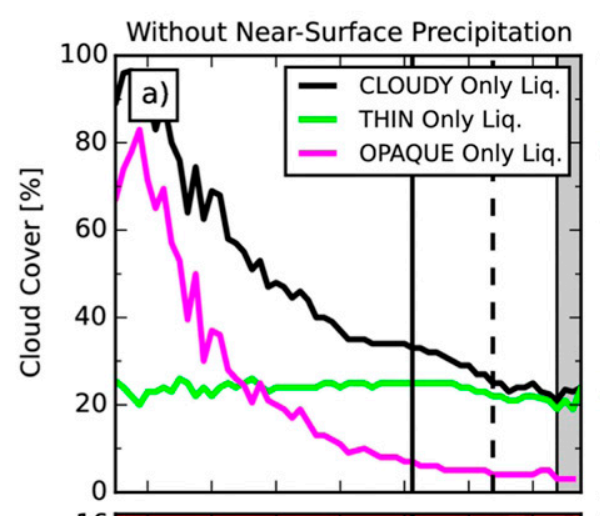

With Near-Surface Precipitation

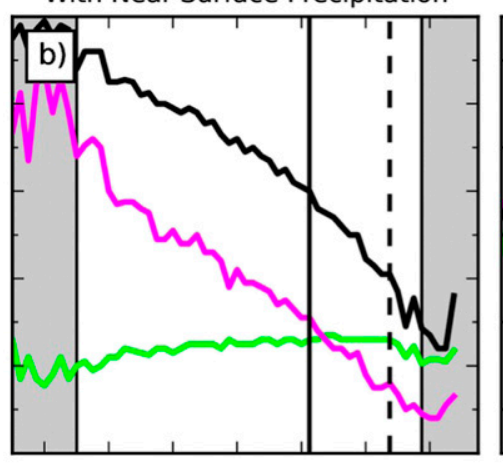

Precipitating - Non-Precipitating
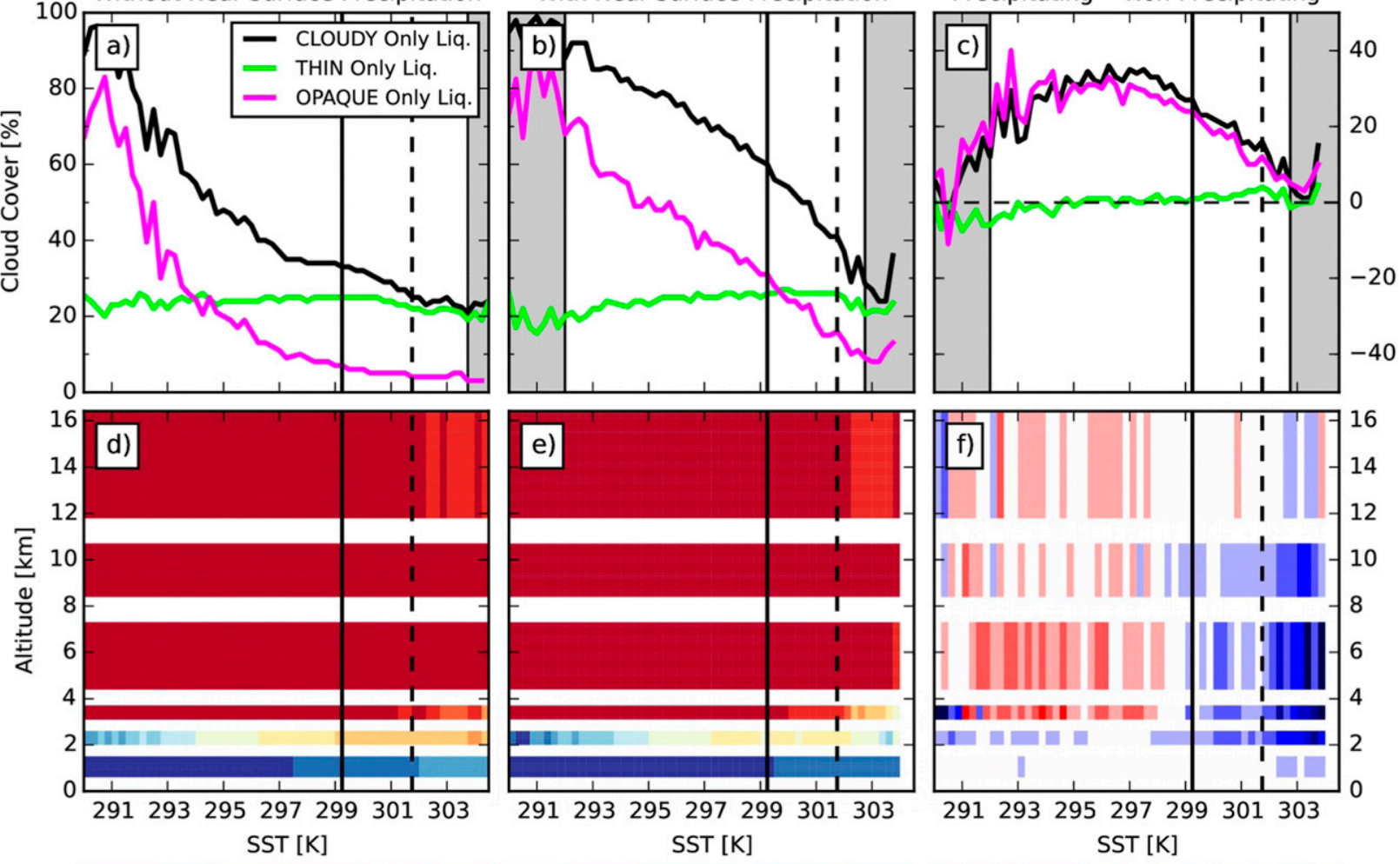

20

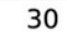

$\begin{array}{ccc}1 & 1 \\ 40 & 50 & 60 \\ \text { Relative Humidity [\%] }\end{array}$

70

$80-6$

Relative RH Difference [\%]

FIG. 5. Evolution of the observed cloud cover and relative humidity with SST within grid boxes in the descending regime $\left(\omega_{500}>\right.$ $20 \mathrm{hPa} \mathrm{day}^{-1}$ ), identified as containing only liquid clouds. (top) Median thin and opaque low liquid cloud covers in grid boxes (a) without near-surface precipitation and (b) with near-surface precipitation, as well as (c) their absolute difference. Note that addition of the green and magenta lines does not equal the black as both opaque and thin clouds are not present in all grid boxes (as evident from their differing number distributions in Fig. 4). Shaded gray areas cover SST bins where the median cloud cover or RH values in the present category were calculated for less than 100 grid boxes. (bottom) Median relative humidity profiles for grid boxes containing only liquid clouds (d) without near-surface precipitation and (e) with near-surface precipitation, as well as (f) their relative difference. Vertical lines are for the same SST thresholds as identified in Fig. 3.

Over the moderate SSTs, the free troposphere moistens (Fig. 9e) in the presence of thin clouds $\left(+1.5 \% \mathrm{~K}^{-1}\right.$; dotted dark blue line) and in clear-sky grid boxes $\left(+5 \% \mathrm{~K}^{-1}\right.$; yellow). The horizontal extent of high ice clouds increases $\left(+0.1\right.$ to $+0.2 \% \mathrm{~K}^{-1}$; not shown) and so does the thin high ice cloud gridbox cover $\left(+3 \% \mathrm{~K}^{-1}\right)$, while the opaque high ice cloud gridbox cover decreases slightly $\left(-2 \% \mathrm{~K}^{-1}\right)$. In contrast, when SST warms $1 \mathrm{~K}$ over the warm SST range, the boundary layer moistens, and the free troposphere dries substantially $\left(-4\right.$ to $\left.-8 \% \mathrm{~K}^{-1}\right)$. The horizontal extent of high ice clouds decreases ( $-0.2 \%$ to $-0.3 \%$; not shown), as does the opaque high ice cloud cover $\left(-13 \% \mathrm{~K}^{-1}\right)$, while the thin high ice cloud cover increases $\left(+6 \% \mathrm{~K}^{-1}\right)$.
The second most important population is high ice clouds without near-surface precipitation (light blue squares and profiles in Fig. 9). Here when SST warms $1 \mathrm{~K}$, the high ice cloud changes (Figs. 9b,c) are like the precipitating category (dark blue squares), suggesting that high ice clouds and near-surface precipitation are poorly coupled. Precipitating high ice clouds (both opaque and thin) dry the free troposphere more than the nonprecipitating counterparts.

We now compare our results in the ascending regime to previous observational work:

- That opaque high ice cloud cover decreases with SST in the ascending regime over the warm SST range 



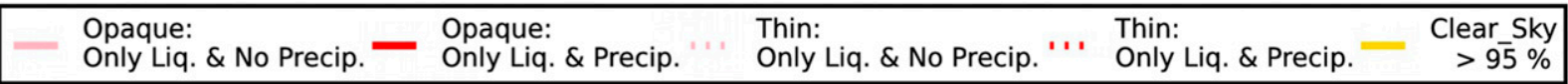

FIG. 6. (top) Change of cloud cover associated with 1-K SST warming. Circles indicate only liquid cloud phase, squares ice phase, and golden pyramids clear-sky cover $>95 \%$ (these are almost invisible as their magnitudes are $<0.5 \% \mathrm{~K}^{-1}$ ). Bullet sizes are weighted by their number contribution to the descending regime: $\omega_{500}>20 \mathrm{hPa}^{-1}{ }^{-1}$. (bottom) Change of RH profiles associated with 1-K SST warming. Values of rate of change are given within the three SST ranges: (a),(d) SST $<299.25 \mathrm{~K}$, (b), (e) $299.25<$ SST $<301.75 \mathrm{~K}$, and (c), (f) SST $>$ $301.75 \mathrm{~K}$. The trend values in the top and bottom panels are calculated from the respective top and bottom panels in Fig. 5.

$(>301.75 \mathrm{~K})$, established in this study, is consistent with Igel et al. (2014), who found anvils (the glaciated part of a deep convective system) to grow smaller and thicker with SST based on CloudSat observations. The CloudSat radar is insensitive to thin clouds, so these were likely poorly represented in the Igel et al. (2014) study. The CALIPSO lidar does however effectively distinguish between opaque and thin clouds in the present study, and thus the increase in thin high ice cloud cover with SST, established in this study, adds new information about the high ice clouds' variation with SST.

- The increase in FTRH around the warm SST threshold $(301.75 \mathrm{~K})$ is consistent with the peak value in column water vapor (CWV) in Dewey and Goldblatt (2018) —although their study was conducted over a wider region than ours $\left(60^{\circ} \mathrm{S}-60^{\circ} \mathrm{N}\right)$ and over both land and ocean surfaces.

- The higher FTRH in the ascending regime (Fig. 8) compared to the descending regime (Fig. 5) seems consistent with the results in Masunaga (2014), who showed with AIRS (NASA's Atmospheric Infrared Sounder) observations that the large-scale updraft in organized systems is generally supplied by moisture through low- and middle-tropospheric convergence, while in contrast free-tropospheric moisture is diverging above shallow cumulus clouds (expected in the descending regime).

- The higher FTRH associated to near-surface precipitation is consistent with Peters and Neelin (2006) and Holloway and Neelin (2009). The latter observed in radiosonde and precipitation gauge measurements 


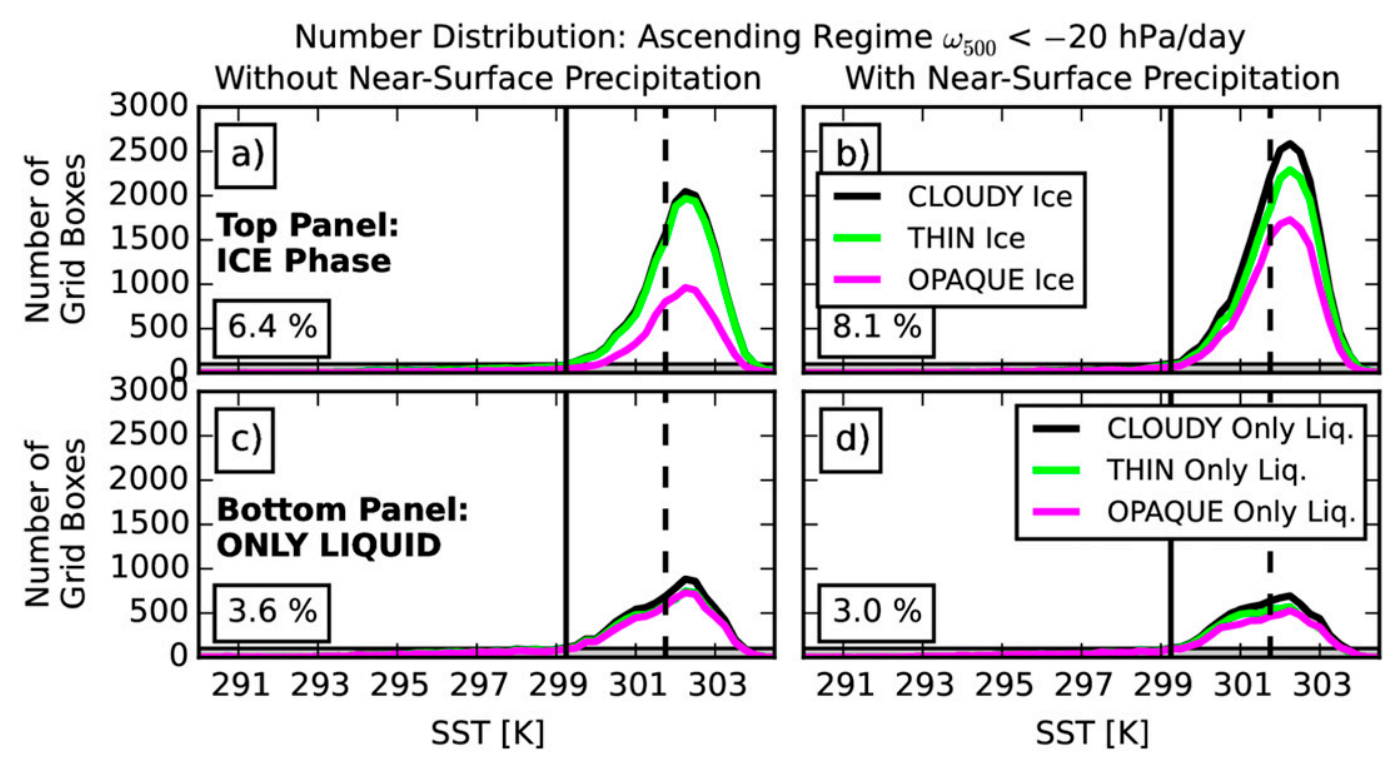

FIG. 7. Gridbox number distributions with SST for the ascending regime: $\omega_{500}<-20 \mathrm{hPa} \mathrm{day}^{-1}$. Occurrence of grid boxes containing (a) ice clouds but no near-surface precipitation, (b) ice clouds and near-surface precipitation, (c) only liquid clouds but no near-surface precipitation, and (d) only liquid clouds and near-surface precipitation. Vertical lines are for the same SST thresholds as identified in Fig. 3.

(from Nauru Island in the western equatorial Pacific) that the transition to deep convection and increased precipitation rates is governed by the CWV above the 850-hPa pressure level, while largely independent of the boundary layer integrated CWV content. Our satellite-based results suggest that these previous local and punctual observations might be representative of tropical ascending regions.

\section{Discussion}

\section{a. Sensitivity of the results to the natural climate variability}

Section 4 establishes new observed relationships between RH, clouds, and near-surface precipitations. Here we examine the sensitivity of these relationships to natural climate variability. For this purpose, we extracted the El Niño period (May 2015-April 2016) and compared it to the full period (May 2012-April 2016) with and without the El Niño period.

There is no notable difference in the $\omega_{500}$ distributions between the three time periods (not shown). Moreover, Figs. 10a-c suggest that there are overall few differences in the individual frequency of occurrence of each atmospheric category between the three time periods. Yet, the relative contribution of grid boxes containing high ice clouds is greater during the El Niño period, at the expense of slightly fewer grid boxes containing low liquid water clouds. Consistently, Figs. 10d-f show that the mean $\mathrm{RH}$ profiles are drier $(-2 \%$ to $-5 \%)$ in the lower troposphere during El Niño, while the midtroposphere is up to $9 \%$ moister.

We also compared the detailed RH, cloud, and nearsurface precipitation analysis within each $\omega_{500}$ regime (Figs. 5 and 8 for the full period) to the El Niño period and found no noticeable differences (Figs. S6-S8). That comparison suggests that the relationship between $\mathrm{RH}$, clouds and near-surface precipitation shown in section 4 describes atmospheric composites that are robust to natural climate variability, as it is only the frequency of occurrence of each atmospheric category that changes (Figs. 10a-c), and not the relationship between $\mathrm{RH}$, clouds, and precipitation.

\section{b. About the intermediate circulation regime}

Section 4 establishes the relationship between RH, clouds, and near-surface precipitation within the descending and ascending regimes, but $42 \%$ of the tropical oceans is sampled within the intermediate regime $(-20<$ $\left.\omega_{500}<20 \mathrm{hPa} \mathrm{day}^{-1}\right)$. Figure $\mathrm{S} 3$ shows that this regime is largely a mixture of the other two. It resembles the descending regime in number distributions of low liquid water clouds (Figs. S3d,e compared to Figs. 4c,d) and the ascending regime for high ice clouds (Figs. S3a,b compared to Figs. 8a,b).

The intermediate regime's SST variations of low liquid water cloud cover and high ice cloud cover within a grid box (Figs. S3j,k and Figs. S3g,h, respectively) are comparable to those in the descending (Figs. 5a,b) and ascending regimes (Figs. 8a,b), respectively. However, opaque high ice cloud 
$\omega_{500}<-20 \mathrm{hPa} /$ day: Clouds in ICE Phase

Evolutions of Cloud Cover and Relative Humidity within a Grid Box

Without Near-Surface Precipitation
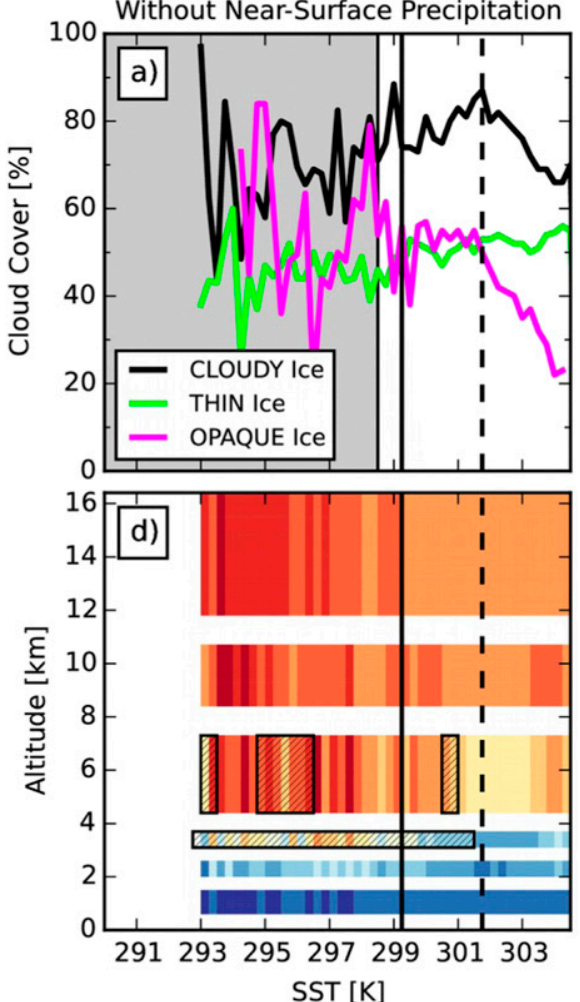

With Near-Surface Precipitation
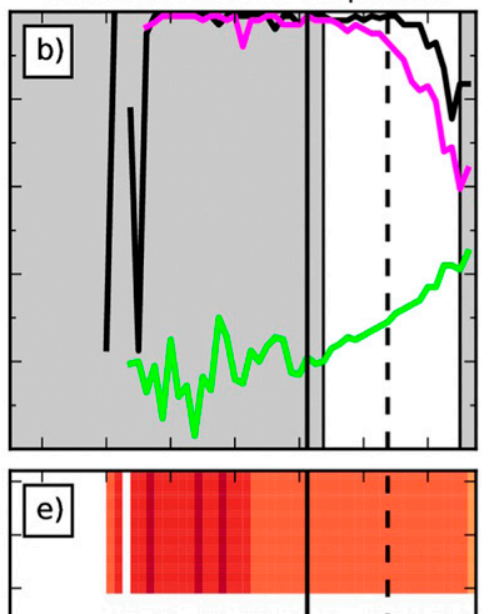

Precipitating - Non-Precipitating
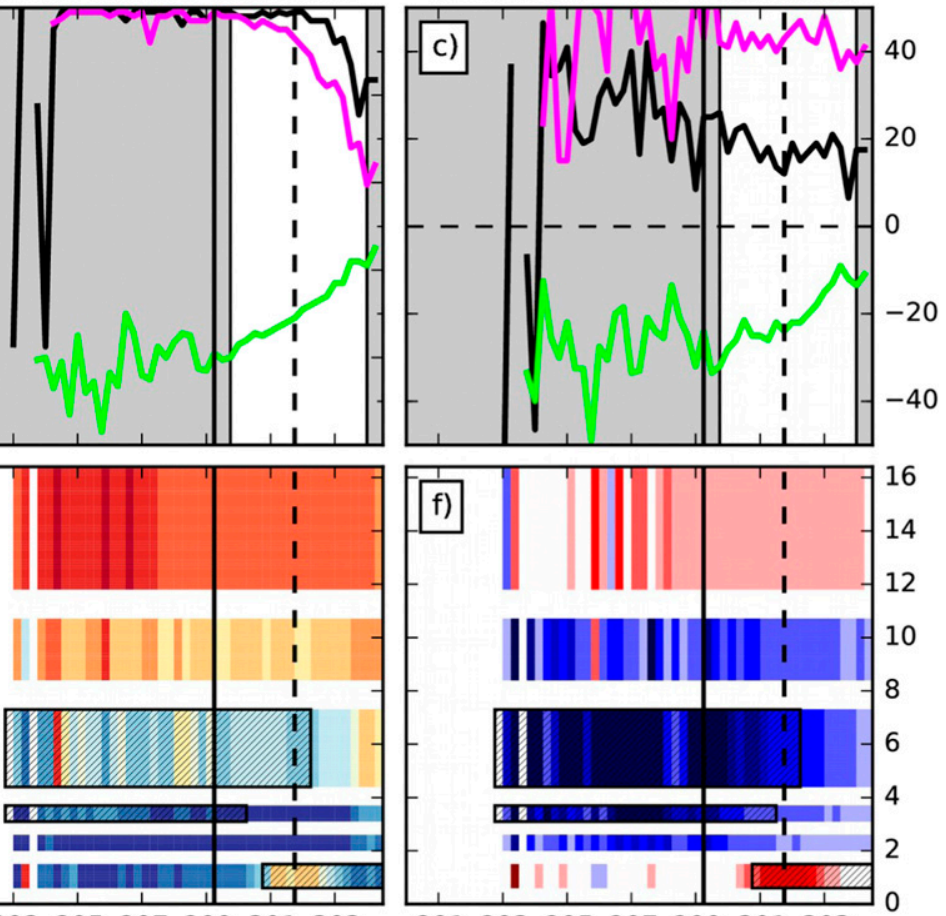

291293295297299301303
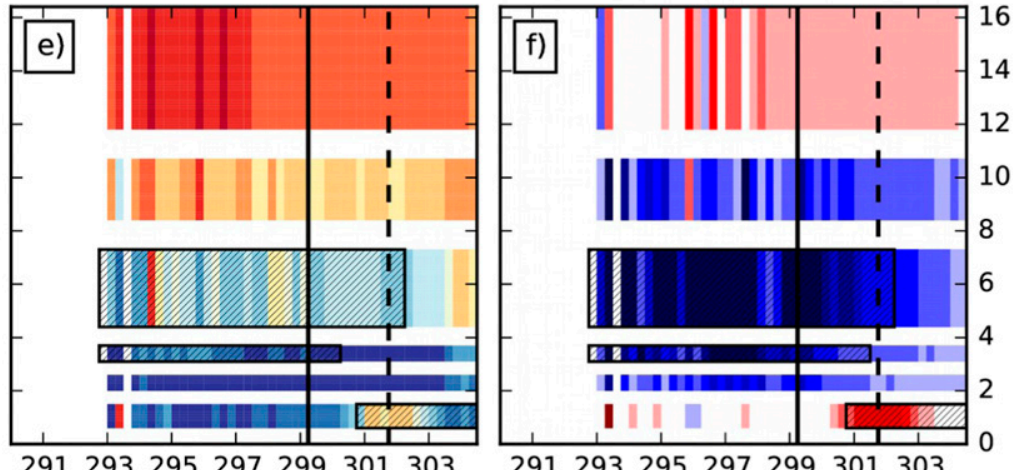

291293295297299301303

SST [K]

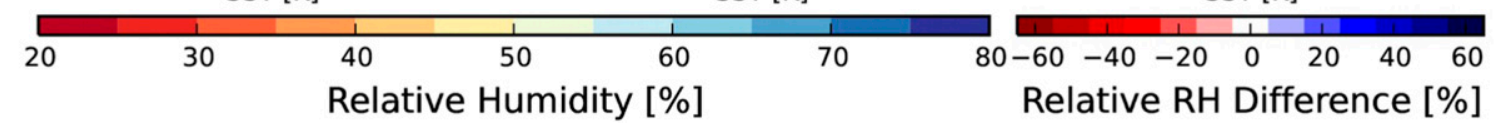

FIG. 8. Evolution of the observed cloud cover and relative humidity with SST within grid boxes in the ascending regime $\left(\omega_{500}<-20 \mathrm{hPa}\right.$ day $\left.{ }^{-1}\right)$, identified as containing ice clouds. (top) Median thin and opaque ice cloud covers in grid boxes (a) without near-surface precipitation and (b) with near-surface precipitation, as well as (c) their absolute difference. Note that addition of the green and magenta lines does not equal the black as both opaque and thin clouds are not present in all grid boxes (as evident from their differing number distributions in Fig. 7). Shaded gray areas cover SST bins where the median cloud cover or RH values in the present category were calculated for less than 100 grid boxes. (bottom) Median relative humidity profiles for grid boxes containing ice clouds (d) without near-surface precipitation and (e) with near-surface precipitation, as well as (f) their relative difference. Black squared and hatched areas indicate layer sections where the interquartile range is greater than $35 \%$, and as such are deemed nonsignificant (supplemental Fig. S11). Vertical lines are for the same SST thresholds as identified in Fig. 3.

cover is smaller $(-20 \%)$ and thin high ice cloud cover larger $(+5 \%)$ in the intermediate regime.

The moisture profiles for the high ice (Figs. S3m,n) and low liquid water (Figs. S3p,q) phase clouds also resemble those of the ascending (Figs. 8c,d) and descending (Figs. 5c,d) regimes, respectively, although the FTRH in the intermediate regime is slightly higher in the low liquid water phase compared to the descending regime, while slightly drier than the ascending regime's high ice phase.

\section{c. Limits of the study}

Heavily precipitating pixels are not represented in the SAPHIR L2B product (Brogniez et al. 2013). Instead the moisture profile in such grid boxes are represented by the average of the surrounding pixels in the rest of the $1^{\circ} \times 1^{\circ}$ grid box, so long as at least $75 \%$ of them are filled with valid pixels. We deem this representation to be statistically meaningful, but are aware of the potentially dry bias in these grid boxes.

Because CloudSat has only provided daytime observations since 2011, the MTCC dataset observes the tropical atmospheric water cycle once daily at one instantaneous moment ( $\sim 1330 \mathrm{LT})$ and cannot be used to observe the diurnal cycle, or any time scale less than $24 \mathrm{~h}$. Thus, the present study is a statistical representation of the atmospheric water cycle's evolution with SST at $1330 \mathrm{LT}$. 

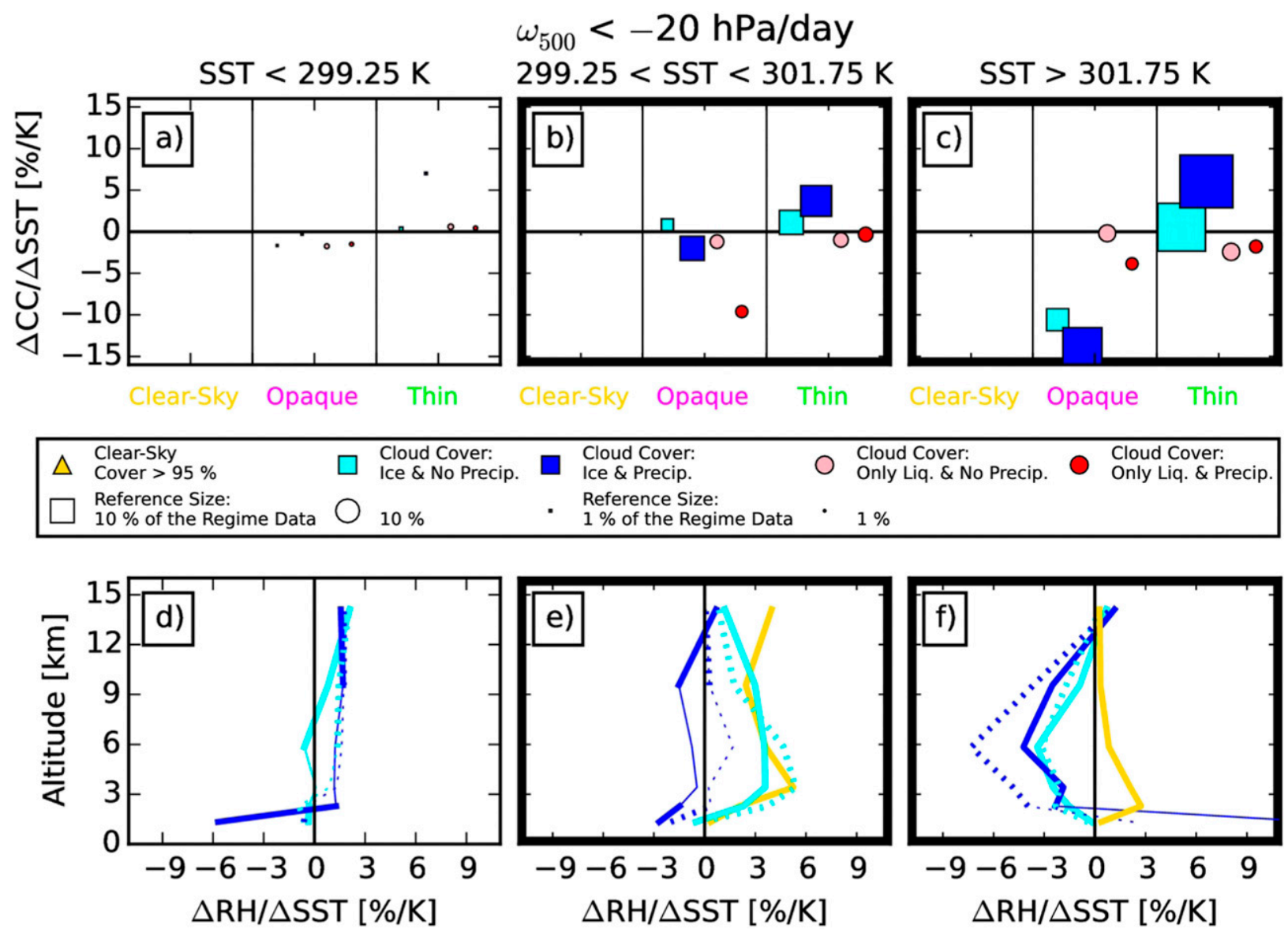

\begin{tabular}{|c|c|c|c|c|c|c|c|}
\hline 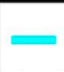 & $\begin{array}{l}\text { Opaque: } \\
\text { Ice \& No Precip. }\end{array}$ & $\begin{array}{l}\text { Opaque: } \\
\text { Ice \& Precip. }\end{array}$ & $\because$ & $\begin{array}{l}\text { Thin: } \\
\text { Ice \& No Precip. }\end{array}$ & 'י & $\begin{array}{l}\text { Thin: } \\
\text { Ice \& Precip. }\end{array}$ & $\begin{array}{r}\text { Clear_Sky } \\
>95 \%\end{array}$ \\
\hline
\end{tabular}

FIG. 9. (top) Change of cloud cover associated with 1-K SST warming. Circles indicate only liquid cloud phase, squares ice phase, and golden pyramids clear-sky cover $>95 \%$ (these are almost invisible as their magnitudes are $<0.5 \% \mathrm{~K}^{-1}$ ). Bullet sizes are weighted by their number contribution to the ascending regime: $\omega_{500}<-20 \mathrm{hPa} \mathrm{day}^{-1}$. (bottom) Change of RH profiles associated with 1-K SST warming. Thick lines in the bottom row show significant values (corresponding to nonhatched areas in Fig. 8), while thin lines show all rates of change. Values of rate of change are given within the three SST ranges: (a),(d) SST < 299.25 K, (b), (e) $299.25<$ SST $<301.75 \mathrm{~K}$, and (c),(f) SST $>301.75 \mathrm{~K}$. The trend values in the top and bottom panels are calculated from the respective top and bottom panels in Fig. 8.

We define our large-scale regimes by monthly mean $\omega_{500}$ values because we do not trust them on shorter time scales. In doing so, however, we ignore fluctuations that occur on shorter time scales, where small-scale convection is probably the most important physical process. Also, monthly mean vertical motion is potentially ambiguous since a single value could equally represent days of strong upward and moderate downward vertical motion during the month or more constant weak upward motion.

The time period in this paper covered only one El Niño event, when in fact they are not all identical. For example, Su and Jiang (2013) showed largely opposite cloud fraction anomalies in the 2007/08 and 2009/10 El Niño events, with larger cloud fractions in the boundary layer and above $14 \mathrm{~km}$ during the 2009/10 El Niño and smaller fractions from 2 to $14 \mathrm{~km}$. During the 2007/08 event, there were instead increased cloud fractions from 2 to $17 \mathrm{~km}$ and little change outside of this range. Takahashi et al. (2013) found similar results using measurements from AIRS and MLS (the Microwave Limb Sounder onboard Aura), as well as higher than normal specific humidities above $300 \mathrm{hPa}$. Therefore, the comparisons made between the El Niño period and the full period are only valid for this El Niño event and should not be taken as proxies for any given event.

\section{d. The super greenhouse effect}

The super greenhouse effect discusses the positive feedback loop on SST induced by reduced OLR due to increasing atmospheric opacity with evaporation rate. It 

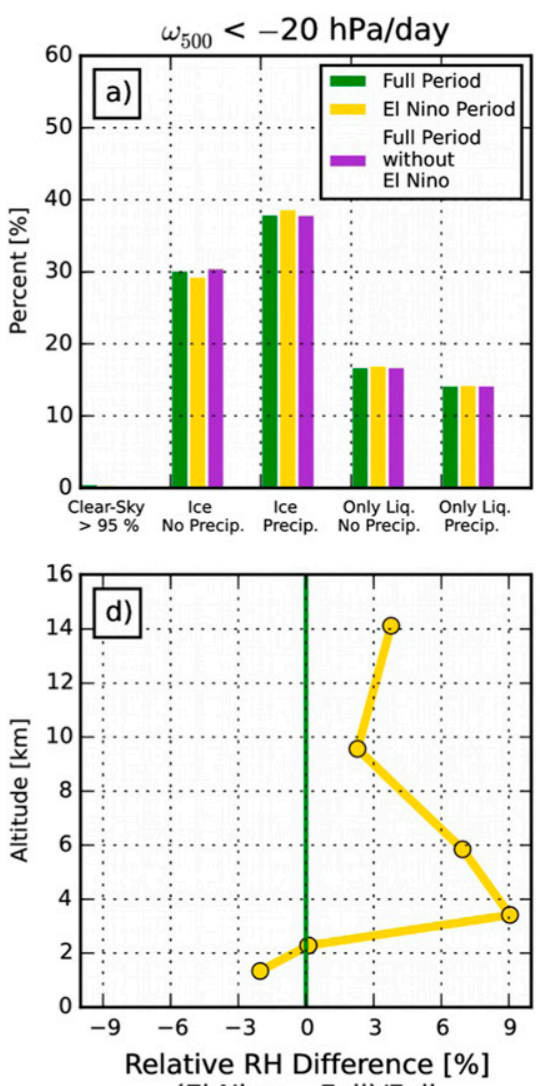

(El Nino - Full)/Full
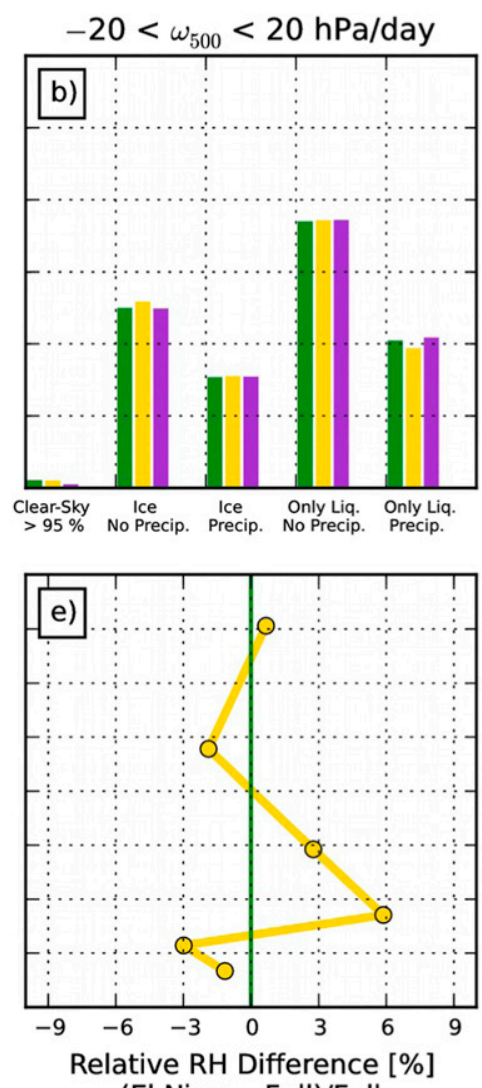

(El Nino - Full)/Ful
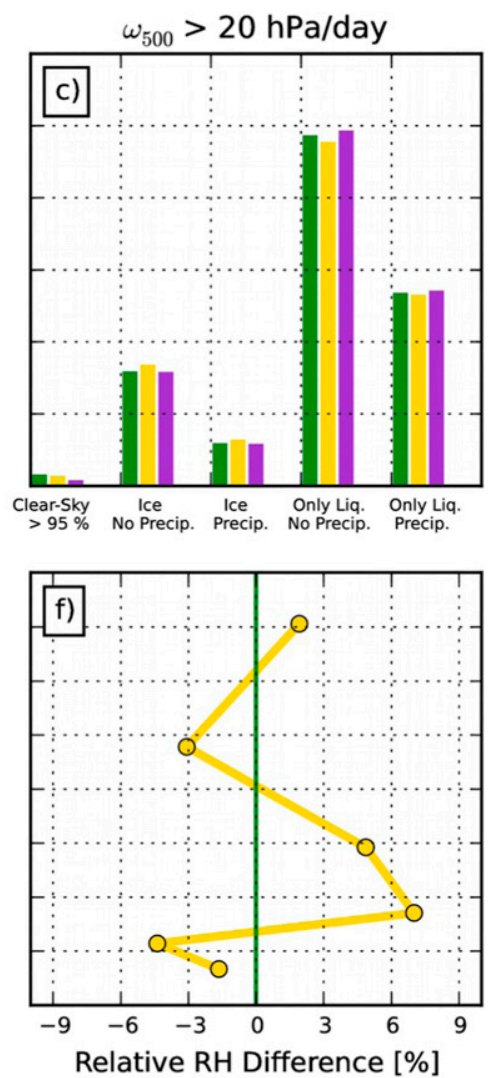

(El Nino - Full)/Full

FIG. 10. (top) Frequency of occurrence of grid boxes within each subcategory, normalized by the total number of grid boxes within the respective vertical pressure velocity regime: (a) $\omega_{500}<-20 \mathrm{hPa} \mathrm{day}^{-1}$, (b) $-20<\omega_{500}<20 \mathrm{hPa} \mathrm{day}^{-1}$, and (c) $\omega_{500}>20 \mathrm{hPa} \mathrm{day}^{-1}$. (bottom) Vertical profiles of mean relative RH difference for the El Niño period minus full period, normalized by the profile of the full period in the same three vertical pressure velocity regimes: (d) $\omega_{500}<-20 \mathrm{hPa} \mathrm{day}^{-1}$, (e) $-20<\omega_{500}<20 \mathrm{hPa} \mathrm{day}^{-1}$, and (f) $\omega_{500}>$ $20 \mathrm{hPa} \mathrm{day}^{-1}$.

has previously been observed under clear-sky conditions (Hallberg and Inamdar 1993; Allan et al. 1999; Stephens et al. 2016), but uncertainties remain for cloudy scenes.

Dewey and Goldblatt (2018) observed that the clearsky OLR (from Clouds and the Earth's Radiant Energy System observations) increases linearly with surface temperature up to $298 \mathrm{~K}$ and decreases for higher surface temperatures, while the clear-sky column water vapor (AIRS observations) increases nonlinearly with surface temperature past this value. In all-sky conditions, they observed that inclusion of clouds decreased the OLR for any given temperature, as well as shifted the peak OLR value toward lower surface temperatures, effectively amplifying the super greenhouse effect compared to clear-sky conditions. They concluded that above some surface temperature threshold, evaporation rates are high enough for the boundary layer to be essentially opaque to the thermally emitted surface radiation. There, the rate of near-surface absorption exceeds that of OLR emission at the top of the atmosphere and the reabsorption drives the rapid surface warming initiating deep convection (Dewey and Goldblatt 2018).

In the present study, we add the simultaneous observations of clouds and moisture with SST to this discussion and observe a boundary layer drying over the warm SST range where deep convection is expected in all regimes (Figs. 5 and 8; see also Fig. S3). We therefore suggest a modification of Dewey and Goldblatt's (2018) conclusion; the increase in column water vapor makes the column-integrated atmosphere opaque to the terrestrial emitted surface radiation, but not the boundary layer alone. In Fig. 8 the transition to deep convection rather appears to be the increasing above $650 \mathrm{hPa}$, as discussed in Holloway and Neelin (2009).

\section{e. Implications of the study}

Figure 11 presents the conceptual evolution of the atmospheric water cycle with SST warming, based on the joint evolutions observed in Figs. 4-9. Under strong descent (Figs. 11a,b), the warming causes a marked 


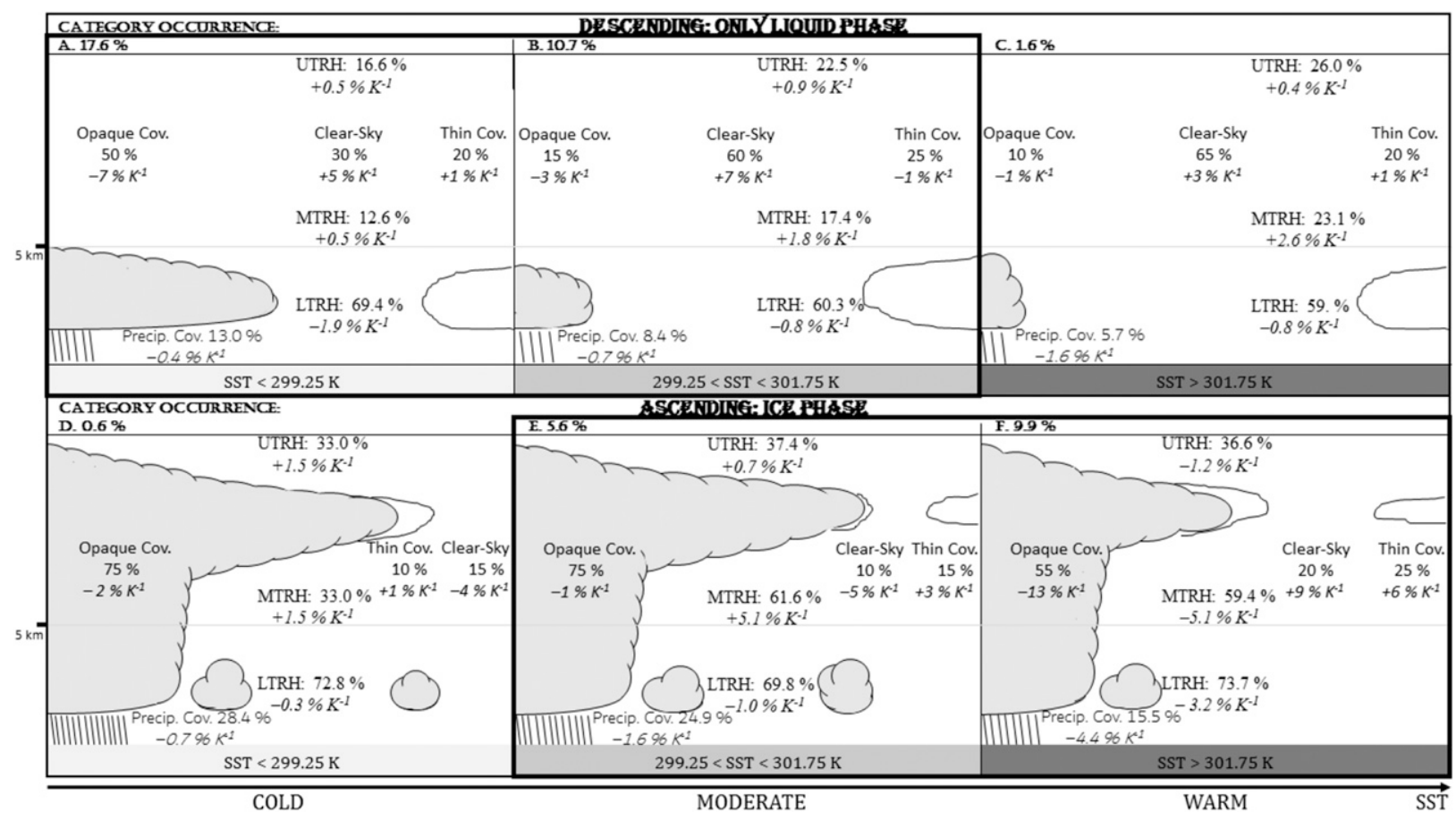

FIG. 11. Schematic illustrating the tropical atmospheric water cycle's evolution with SST. (top) Low liquid clouds in the descending regime $\left(\omega_{500}>20 \mathrm{hPa} \mathrm{day}^{-1}\right)$. (bottom) High ice clouds in the ascending regime $\left(\omega_{500}<-20 \mathrm{hPa} \mathrm{day}^{-1}\right)$. Mean values and illustrations are approximated from Fig. 5 for the top row and Fig. 8 for the bottom row, while trend values from Fig. 6 for the top row and Fig. 9 for the bottom row. Mean values are given in normal font and the rate of change of each parameter with 1-K warming is given in italics. Values of category occurrence indicate how much of the tropical ocean is covered by that category and SST range in the MTCC dataset. Abbreviations: UTRH, MTRH, and LTRH stand for upper-, middle-, and lower-tropospheric RH, respectively; "Precip." stands for nearsurface precipitation and "Cov." for cover within a grid box.

decrease in opaque low liquid water cloud cover and an increase in clear-sky cover, slightly compensated by a moister free troposphere. Together, these two evolutions should lead to increased OLR over the cold SST range [as SST $<298 \mathrm{~K}$ according to Dewey and Goldblatt (2018)]. However, because these are low clouds confined to the lower troposphere, the decreasing cloudiness might not lead to much higher OLR.

Under strong ascent (Figs. 11e,f), the analysis suggests that over the moderate and warm SST ranges, opaque high ice cloud cover is smaller for warmer SSTs. This decrease is accompanied by an increase in thin high ice cloud cover. In fact, if only grid boxes guaranteed to contain opaque high ice clouds are considered, the increase in thin high ice cloud cover equals the decrease in opaque high ice cloud cover (not shown), so that the total high ice cloud cover is always $100 \%$. This observation could be a valuable constraint for climate models. The near-surface precipitation cover decreases acceleratingly with warming. The OLR should increase in accordance with both decreasing cloudiness and increasing FTRH for SSTs $<298 \mathrm{~K}$ (Dewey and Goldblatt 2018), but over the moderate and warm SST ranges the evolution of OLR is less ambiguous. In heavily precipitating scenes (not shown), FTRH $\gtrsim 65 \%$, the opaque high ice cloud cover is $100 \%$ over the cold and moderate SST ranges and $\geq 80 \%$ over the warm. In these situations, the total high ice cloud cover is always $100 \%$, so OLR must be substantially reduced.

Together, the decreasing opaque high ice cloud cover $\left(-13 \% \mathrm{~K}^{-1}\right)$ and drying midtroposphere $\left(-5 \% \mathrm{~K}^{-1}\right)$ over the warm SST range (Fig. 10f) support the iris hypothesis (Lindzen et al. 2001). However, the increasing thin high ice cloud cover $\left(+6 \% \mathrm{~K}^{-1}\right)$ and decreasing near-surface precipitation cover $\left(-4.4 \% \mathrm{~K}^{-1}\right)$ suggest that the decreasing opaque high ice cloud cover is not compensated by increased precipitation (as suggested in the iris hypothesis), but rather by increasing thin high ice cloud cover.

\section{Conclusions}

We build a composite synergistic dataset (MTCC) of instantaneous observations (once daily at $1330 \mathrm{LT}$ ) of RH (Megha-Tropiques), clouds (CALIPSO), and 
near-surface precipitation (CloudSat) to analyze SST variations of the tropical atmospheric water cycle at the instantaneous scale. We only consider fully oceanic grid boxes of $1^{\circ} \times 1^{\circ}$ horizontal resolution and partition the tropical atmosphere into three vertical pressure velocity regimes (descending, ascending, intermediate), with cloudy grid boxes categorized by phase (high ice or low liquid), opacity (opaque or thin), and the presence of nearsurface precipitation.

Cloudy grid boxes without near-surface precipitation dominate the descending and intermediate regimes, while precipitating grid boxes dominate the ascending regime. Clear-sky grid boxes $(<5 \%$ cloudiness) are extremely rare, meaning that clouds are almost always present. We identify two SST thresholds, based on the median cloud cover evolutions, with local minima and maxima at the cold $(299.25 \mathrm{~K})$ and warm $(301.75 \mathrm{~K})$ thresholds. These thresholds fall within the SST ranges where previous studies have located the onset of deep convection and the peak frequency of occurrence of deep convection, respectively. Over the warm SST range $(\mathrm{SST}>301.75 \mathrm{~K})$, the total cloud cover decreases with SST in all three regimes.

The descending regime with low liquid water clouds dominates the cold SST range $(<299.25 \mathrm{~K})$ where the free troposphere is always dry $(\sim 20 \%)$. The low liquid water cloud cover variations are governed by the opaque low liquid water cloud cover $\left(-8 \% \mathrm{~K}^{-1}\right)$, as the thin liquid cloud cover stays largely constant ( $\sim 20 \%)$. In the presence of near-surface precipitation, the opaque and total low liquid water cloud covers are wider and the FTRH moister over the moderate and warm SSTs, while drier over the cold SSTs.

The ascending regime with high ice clouds dominates the warm SST range, although low liquid water clouds are frequently present below. By the onset of deep convection, humidity increases with increasing SST in the lower free troposphere and peaks around the warm SST threshold. The present study confirms the decrease in opaque high ice cloud cover over the warm SST range, identified in previous studies, but shows that this decrease is compensated by increasing thin high ice cloud cover and perhaps not by increasing precipitation (as suggested in the iris hypothesis). Over the whole SST range, the free troposphere is moister and the opaque high ice cloud cover larger in the presence of near-surface precipitation (at the expense of smaller thin high ice clouds).

The intermediate regime has been the focus of fewer previous publications. We conclude that this regime is largely a mixture of the ascending and descending regimes, where the low liquid water cloud cover is slightly wider, and the high ice cloud cover smaller, compared to the descending and ascending regimes, respectively. The moisture profiles also typically align themselves as an average between the other two regimes.

The clear-sky cover increases in all regimes over the warm SST range, but the free troposphere moistens when low liquid water clouds are present and dries in the presence of high ice clouds. The evolution of OLR with warming is therefore not unambiguous from our results but requires a quantification. The ScaRaB payload onboard Megha-Tropiques measures top-ofthe-atmosphere radiative fluxes and will be combined with more precise cloud altitudes and emission temperatures from CALIPSO (GOCCP) to get a more three-dimensional view of the tropical clouds and their interactions with radiation.

Acknowledgments. We thank NASA, CNES, Climserv, and ICARE for satellite data accessibility and direct special thanks to Patrick Raberanto (LMD/IPSL, Sorbonne Université, École Polytechnique, CNRS, France), Artem Feofilo (LMD/IPSL, Sorbonne Université, École Polytechnique, CNRS, France), and Christophe Dufour (LATMOS/IPSL, Université de Versailles Saint-Quentinen-Yvelines, CNRS, Guyancourt, France) for having prepared the $1^{\circ} \times 1^{\circ}$ GOCCP, 2C-PRECIP-COLUMN CloudSat, and SAPHIR L2B products, respectively, used to build the MTCC dataset.

We are also very grateful to Tristan L'Ecuyer (Department of Atmospheric and Oceanic Sciences, University of Wisconsin-Madison, Madison, USA) for several fruitful scientific discussions.

We thank the editor and the reviewers for their comments and encouragements that helped us to clarify our results.

\section{REFERENCES}

Allan, R. P., and B. J. Soden, 2008: Atmospheric warming and the amplification of precipitation extremes. Science, 321, 14811484, https://doi.org/10.1126/science.1160787.

, K. P. Shine, A. Slingo, and J. A. Pamment, 1999: The dependence of clear-sky outgoing long-wave radiation on surface temperature and relative humidity. Quart. J. Roy. Meteor. Soc., 125, 2103-2126, https://doi.org/10.1002/qj.49712555809.

—, C. Liu, M. Zahn, D. A. Lavers, E. Koukouvagias, and A. Bodas-Salcedo, 2014: Physically consistent responses of the global atmospheric hydrological cycle in models and observations. Surv. Geophys, 35, 533-552, https://doi.org/10.1007/ s10712-012-9213-z.

Aumann, H. H., A. Ruzmaikin, and A. Behrangi, 2017: Increase in the frequency of tropical deep convective clouds with global warming. Atmos. Chem. Phys. Discuss., https://doi.org/10.5194/ acp-2017-135, in press.

Behrangi, A., T. Kubar, and B. Lambrigtsen, 2012: Phenomelogical description of tropical clouds using CloudSat cloud classification. Mon. Wea. Rev., 140, 3235-3249, https://doi.org/10.1175/ MWR-D-11-00247.1. 
Bony, S., and J.-L. Dufresne, 2005: Marine boundary layer clouds at the heart of tropical cloud feedback uncertainties in climate models. Geophys. Res. Lett., 32, L20806, https://doi.org/ 10.1029/2005GL023851.

- — - and H. Le Treut, J.-J. Morcrette, and C. Senior 2004: On dynamic and thermodynamic components of cloud changes. Climate Dyn., 22, 71-86, https://doi.org/10.1007/s00382-0030369-6.

- B. Stevens, D. Coppin, T. Becker, K. A. Reed, A. Voigt, and B. Medeiros, 2016: Thermodynamic control of anvil cloud amount. Proc. Natl. Acad. Sci. USA, 113, 8927-8932, https:// doi.org/10.1073/pnas.1601472113.

Brogniez, H., P.-E. Kirstetter, and L. Eymard, 2013: Expected improvements in the atmospheric humidity profile retrieval using the Megha-Tropiques microwave payload. Quart. J. Roy. Meteor. Soc., 139, 842-851, https://doi.org/10.1002/qj.1869.

—, R. Fallourd, C. Mallet, R. Sivira, and C. Dufour, 2016: Estimating confidence intervals around relative humidity profiles from satellite observations: Applications to the SAPHIR sounder. J. Atmos. Oceanic Technol., 33, 1005-1022, https:// doi.org/10.1175/JTECH-D-15-0237.1.

Buehler, S. A., M. Kuvatov, V. O. John, M. Milz, B. J. Soden, D. L. Jackson, and J. Notholt, 2008: An upper tropospheric humidity data set from operational satellite microwave data. J. Geophys. Res., 113, D14110, https://doi.org/10.1029/2007JD009314.

Burns, B. A., X. Wu, and G. R. Diak, 1997: Effects of precipitation and cloud ice on brightness temperatures in AMSU moisture channels. IEEE Trans. Geosci. Remote Sens., 35, 1429-1437, https://doi.org/10.1109/36.649797.

Ceppi, P., F. Brient, M. D. Zelinka, and D. L. Hartmann, 2017: Cloud feedback mechanisms and their representaion in global climate models. Wiley Interdiscip. Rev.: Climate Change, $\mathbf{8}$, e465, https://doi.org/10.1002/wcc.465.

Cesana, G., and H. Chepfer, 2012: How well do climate models simulate cloud vertical structure? A comparison between CALIPSOGOCCP satellite observations and CMIP5 models. Geophys. Res. Lett., 39, L20803, https://doi.org/10.1029/2012GL053153.

- and — 2013: Evaluation of the cloud thermodynamic phase in a climate model using CALIPSO-GOCCP. J. Geophys. Res. Atmos., 118, 7922-7937, https://doi.org/10.1002/JGRD.50376.

_ J. E. Kay, H. Chepfer, J. M. English, and G. de Boer, 2012: Ubiquitous low-level liquid-containing Arctic clouds: New observations and climate model constraints from CALIPSOGOCCP. Geophys. Res. Lett., 39, L20804, https://doi.org/ 10.1029/2012GL053385.

_ - and Coauthors, 2016: Using in-situ airborne measurements to evaluate three cloud phase products derived from CALIPSO. J. Geophys. Res. Atmos., 121, 5788-5808, https://doi.org/ 10.1002/2015JD024334.

Chepfer, H., S. Bony, D. Winker, G. Cesana, J. L. Dufresne, P. Minnis, C. J. Stubenrauch, and S. Zeng, 2010: The GCM-Oriented CALIPSO Cloud Product (CALIPSO-GOCCP). J. Geophys. Res., 115, D00H16, https://doi.org/10.1029/2009JD012251.

, G. Cesana, D. Winker, B. Getzewich, M. Vaughan, and Z. Liu, 2013: Comparison of two different cloud climatologies derived from CALIOP-attenuated backscattered measurements (level 1): The CALIPSO-ST and the CALIPSOGOCCP. J. Atmos. Oceanic Technol., 30, 725-744, https:// doi.org/10.1175/JTECH-D-12-00057.1.

, V. Noel, D. Winker, and M. Chiriaco, 2014: Where and when will we observe cloud changes due to climate warming? Geophys. Res. Lett., 41, 8387-8395, https://doi.org/10.1002/ 2014GL061792.
Dee, D. P., and Coauthors, 2011: The ERA-Interim reanalysis: Configuration and performance of the data assimilation system. Quart. J. Roy. Meteor. Soc., 137, 553-597, https://doi.org/ 10.1002/qj.828.

Dewey, M., and C. Goldblatt, 2018: Evidence for radiative-convective bistability in tropical atmospheres. Geophys. Res. Lett., 45, 10 673-10 681, https://doi.org/10.1029/2018GL078903.

Eastman, R., S. G. Warren, and C. J. Hahn, 2011: Variations in cloud cover and cloud types over the ocean from surface observations, 1945-2008. J. Climate, 24, 5914-5934, https:// doi.org/10.1175/2011JCLI3972.1.

Evans, J. L., and C. C. Webster, 2014: A variable sea surface temperature threshold for tropical convection. Aust. Meteor. Oceanogr. J., 64, S1-S8, https://doi.org/10.22499/2.6401.007.

Fu, Q., M. Baker, and D. L. Hartmann, 2002: Tropical cirrus and water vapor: An effective Earth infrared iris feedback? Atmos. Chem. Phys., 2, 31-37, https://doi.org/10.5194/acp-2-31-2002.

Gettelman, A., W. D. Collins, E. J. Fetzer, A. Eldering, F. W. Irion, P. B. Duffy, and G. Bala, 2006: Climatology of upper-tropospheric relative humidity from the Atmospheric Infrared Sounder and implications for climate. J. Climate, 19, 6104-6121, https://doi.org/ 10.1175/JCLI3956.1.

Goldblatt, C., T. D. Robinson, K. J. Zahnle, and D. Crisp, 2013: Low simulated radiation limit for runaway greenhouse climates. Nat. Geosci., 6, 661-667, https://doi.org/10.1038/ngeo1892.

Greenwald, T. J., and S. A. Christopher, 2002: Effect of cold clouds on satellite measurements near $183 \mathrm{GHz}$. J. Geophys. Res., 107, 4170, https://doi.org/10.1029/2000JD000258.

Guzman, R., and Coauthors, 2017: Direct atmosphere opacity observations from CALIPSO provide new constraints on cloud-radiation interactions. J. Geophys. Res. Atmos., 122, 1066-1085, https://doi.org/10.1002/2016JD025946.

Hallberg, R., and A. K. Inamdar, 1993: Observations of seasonal variations in atmospheric greenhouse trapping and its enhancement at high sea surface temperature. J. Climate, $\mathbf{6}$, 920-931, https://doi.org/10.1175/1520-0442(1993)006<0920: OOSVIA $>2.0 . \mathrm{CO} ; 2$.

Hartmann, D., and M. L. Michelsen, 2002: No evidence for iris. Bull. Amer. Meteor. Soc., 83, 249-254, https://doi.org/10.1175/ 1520-0477(2002)083<0249:NEFI >2.3.CO;2.

Haynes, J. M., T. S. L'Ecuyer, G. L. Stephens, S. D. Miller, C. Mitrescu, N. B. Wood, and S. Tanelli, 2009: Rainfall retrieval over the ocean with spaceborne W-band radar. J. Geophys. Res., 114, D00A22, https://doi.org/10.1029/2008JD009973.

,,-- D. Vane, G. Stephens, and D. Reinke, 2013: Level 2CPrecipitation Column Algorithm Product Process Description and Interface Control Document. 17 pp., http://www.cloudsat. cira.colostate.edu/sites/default/files/products/files/2C-PRECIPCOLUMN_PDICD.P2_R04.20130124.pdf.

Hoffmann, L., and Coauthors, 2018: From ERA-Interim to ERA5: Considerable impact of ECMWF's next-generation reanalysis on Lagrangian transport simulations. Atmos. Chem. Phys., 19, 3097-3124, https://doi.org/10.5194/ACP-19-3097-2019.

Holloway, C. E., and J. D. Neelin, 2009: Moisture vertical structure, column water vapor, and tropical deep convection. J. Atmos. Sci., 66, 1665-1683, https://doi.org/10.1175/2008JAS2806.1.

Houze, R. A., K. L. Rasmussen, M. D. Zuluaga, and S. R. Brodzik, 2015: The variable nature of convection in the tropics and subtropics: A legacy of 16 years of the Tropical Rainfall Measuring Mission satellite. Rev. Geophys., 53, 994-1021, https://doi.org/10.1002/2015RG000488.

Igel, M. R., A. J. Drager, and S. C. van den Heever, 2014: A CloudSat cloud object partitioning technique and assessment 
and integration of deep convective anvil sensitivities to sea surface temperature. J. Geophys. Res. Atmos., 119, 1051510 535, https://doi.org/10.1002/2014JD021717.

Inamdar, A. K., and V. Ramanathan, 1998: Tropical and global scale interactions among water vapor, atmospheric greenhouse effect and surface temperature. J. Geophys. Res., 103, 32 177-32 194, https://doi.org/10.1029/1998JD900007.

Johnson, N. C., and S.-P. Xie, 2010: Changes in the sea surface temperature threshold for tropical convection. Nat. Geosci., $\mathbf{3}$, 842-845, https://doi.org/10.1038/ngeo1008.

Kamae, Y., T. Ogura, H. Shiogama, and M. Watanabe, 2016: Recent progress toward reducing the uncertainty in tropical low cloud feedback and climate sensitivity: A review. Geosci. Lett., 3, 17, https://doi.org/10.1186/s40562-016-0053-4.

Kay, J. E., T. L'Ecuyer, A. Pendergrass, H. Chepfer, R. Guzman, and V. Yettella, 2018: Scale-aware and definition-aware evaluation of modeled near-surface precipitation frequency using CloudSat observations. J. Geophys. Res. Atmos., 123, 4294-4309, https://doi.org/10.1002/2017JD028213.

Klein, S. A., A. Hall, J. R. Norris, and R. Pincus, 2017: Low-cloud feedbacks from cloud-controlling factors: A review. Surv. Geophys., 38, 1307-1329, https://doi.org/10.1007/s10712-0179433-3.

Konsta, D., H. Chepfer, and J.-L. Dufresne, 2012: A process oriented characterization of tropical oceanic clouds for climate model evaluation, based on a statistical analysis of daytime A-Train observations. Climate Dyn., 39, 2091-2108, https:// doi.org/10.1007/s00382-012-1533-7.

Läderach, A., and C. C. Raible, 2013: Lower-tropospheric humidity: Climatology, trends and the relation to the ITCZ. Tellus, 65A, 20413, https://doi.org/10.3402/tellusa.v65i0.20413.

Li, J.-L. F., and Coauthors, 2012: An observationally based evaluation of cloud ice water in CMIP3 and CMIP5 GCMs and contemporary reanalyses using contemporary satellite data. J. Geophys. Res., 117, D16105, https://doi.org/10.1029/ 2012JD017640.

Li, R. L., T. Storelvmo, A. V. Fedorov, and Y.-S. Choi, 2019: A positive IRIS feedback: Insights from climate simulations with temperature-sensitive cloud-rain conversion. J. Climate, 32, 5305-5324, https://doi.org/10.1175/JCLI-D-18-0845.1.

Lin, B., B. A. Wielicki, P. Minnis, L. Chambers, K.-M. Xu, and Y. Hu, 2006: The effect of environmental conditions on tropical deep convective systems observed from the TRMM satellite. J. Climate, 19, 5745-5761, https://doi.org/10.1175/ JCLI3940.1.

- - - L. H. Chambers, Y. Hu, and K.-M. Xu, 2002: The iris hypothesis: A negative or positive cloud feedback? J. Climate, 15, 3-7, https://doi.org/10.1175/1520-0442(2002)015<0003: TIHANO $>2.0 . \mathrm{CO} ; 2$.

Lindzen, R. S., M.-D. Chou, and A. Y. Hou, 2001: Does the Earth have an adaptive infrared iris? Bull. Amer. Meteor. Soc., 82, 417-432, https://doi.org/10.1175/1520-0477(2001)082<0417: DTEHAA $>2.3 . \mathrm{CO} ; 2$.

Masunaga, H., 2014: Free-tropospheric moisture convergence and tropical convective regimes. Geophys. Res. Lett., 41, 86118618, https://doi.org/10.1002/2014GL062301.

Mauritsen, T., and B. Stevens, 2015: Missing iris effect as a possible cause of muted hydrological change and high climate sensitivity in models. Nat. Geosci., 8, 346-351, https://doi.org/ 10.1038/ngeo2414.

Noel, V., H. Chepfer, M. Chiriaco, and J. Yorks, 2018: The diurnal cycle of cloud profiles over land and ocean between $51^{\circ} \mathrm{S}$ and $51^{\circ} \mathrm{N}$, seen by the CATS spaceborne lidar from the
International Space Station. Atmos. Chem. Phys., 18, 94579473, https://doi.org/10.5194/acp-18-9457-2018.

Peters, O., and J. D. Neelin, 2006: Critical phenomena in atmospheric precipitation. Nat. Phys., 2, 393-396, https://doi.org/ 10.1038/nphys314.

Pierrehumbert, R. T., 1995: Thermostats, radiator fins, and the local runaway greenhouse. J. Atmos. Sci., 52, 1784-1806, https://doi.org/10.1175/1520-0469(1995)052<1784:TRFATL $>2$. $0 . \mathrm{CO} ; 2$.

Ramanathan, V., and W. Collins, 1991: Thermodynamic regulation of ocean warming by cirrus clouds deduced from observations of the 1987 El Niño. Nature, 351, 27-32, https://doi.org/10.1038/351027a0.

Rapp, A. D., C. Kummerow, W. Berg, and B. Griffith, 2005: An evaluation of the proposed mechanism of the adaptive infrared iris hypothesis using TRMM VIRS and PR measurements. J. Climate, 18, 4185-4194, https://doi.org/10.1175/JCLI3528.1.

Roca, R., M. Viollier, L. Picon, and M. Desbois, 2000: A multisatellite analysis of deep convection and its moist environment over the Indian Ocean during the winter monsoon. J. Geophys. Res., 107, 8012, https://doi.org/10.1029/2000JD000040.

, and Coauthors, 2015: The Megha-Tropiques mission: A review after three years in orbit. Front. Earth Sci., 3, 17, https:// doi.org/10.3389/feart.2015.00017.

Ross, R. J., W. P. Elliott, and D. J. Seidel, 2002: Lower-tropospheric humidity-temperature relationships in radiosonde observations and atmospheric general circulation models. J. Hydrometeor., 3, 26-38, https://doi.org/10.1175/15257541(2002)003<0026:LTHTRI > 2.0.CO;2.

Sabin, T. P., C. A. Babu, and P. V. Joseph, 2013: SST-convection relation over tropical oceans. Int. J. Climatol., 33, 1424-1435, https://doi.org/10.1002/joc.3522.

Sivira, R., H. Brogniez, C. Dufour, and S. Cloché, 2017: MeghaTropiques product definition document instantaneous nonprecipitating conditions Level 2 products relative humidity profile derived from SAPHIR SAPHIR-L2-RH Version 1 Release 5.13 pp., http://www.icare.univ-lille1.fr/projects_data/ $\mathrm{mt} /$ /docs/PDD_SAPHIR-L2-RH_V1_R5.pdf.

, C. Mallet, and Y. Oussar, 2015: A layer-average relative humidity profile retrieval for microwave observations: Design and results for the Megha-Tropiques payload. Atmos. Meas. Tech., 8, 1055-1071, https://doi.org/10.5194/amt-8-1055-2015.

Smalley, M., T. L'Ecuyer, M. Lebsock, and J. Haynes, 2014: A comparison of precipitation occurrence from the NCEP stage IV QPE product and the CloudSat cloud profiling radar. J. Hydrometeor., 15, 444-458, https://doi.org/10.1175/JHM-D-13-048.1.

Stephens, G. L., B. H. Kahn, and M. Richardson, 2016: The super greenhouse effect in a changing climate. J. Climate, 29, 54695482, https://doi.org/10.1175/JCLI-D-15-0234.1.

Su, H., and J. H. Jiang, 2013: Tropical clouds and circulation changes during the 2007/08 and 2009/10 El Niños. J. Climate, 26, 399-413, https://doi.org/10.1175/JCLI-D-12-00152.1. , and Coauthors, 2008: Variations of tropical upper tropospheric clouds with sea surface temperature and implications of radiative effects. J. Geophys. Res., 113, D10211, https:// doi.org/10.1029/2007JD009624.

— - and Coauthors, 2017: Tightening of tropical ascent and high clouds key to precipitation change in a warmer climate. Nat. Commun., 8, 15771, https://doi.org/10.1038/NCOMMS15771.

Takahashi, H., H. Su, J. H. Jiang, Z. J. Luo, S.-P. Xie, and J. Hafner, 2013: Tropical water vapor variations during the 2006-2007 and 2009-2010 El Niños: Satellite observation and GFDL AM2.1 simulation. J. Geophys. Res. Atmos., 118, 8910-8920, https://doi.org/10.1002/JGRD.50684. 
Trenberth, K. E., D. P. Stepaniak, and J. M. Caron, 2000: The global monsoon as seen through the divergent atmospheric circulation. J. Climate, 13, 3969-3993, https://doi.org/10.1175/ 1520-0442(2000)013<3969:TGMAST >2.0.CO;2.

Vaillant de Guélis, T., H. Chepfer, V. Noel, R. Guzman, P. Dubuisson, D. M. Winker, and S. Kato, 2017: The link between outgoing longwave radiation and the altitude at which a spaceborne lidar beam is fully attenuated. Atmos. Meas. Tech., 10, 4659-4685, https://doi.org/10.5194/amt10-4659-2017.

Waliser, D. E., N. E. Graham, and C. Gautier, 1993: Comparison of the high reflective cloud and outgoing longwave radiation datasets for use in estimation tropical deep convection. J. Climate, 6, 331-353, https://doi.org/10.1175/1520-0442(1993) 006<0331:COTHRC $>2.0$. CO;2.

Winker, D. M., M. A. Vaughan, A. Omar, Y. Hu, K. A. Powell, Z. Liu, W. H. Hunt, and S. A. Young, 2009: Overview of the CALIPSO mission and CALIOP data processing algorithms. J. Atmos. Oceanic Technol., 26, 2310-2323, https://doi.org/ 10.1175/2009JTECHA1281.1.

Zhai, C., J. H. Jiang, and H. Su, 2015: Long-term cloud change imprinted in seasonal cloud variation: More evidence of high climate sensitivity. Geophys. Res. Lett., 42, 8729-8737, https:// doi.org/10.1002/2015GL065911. 